\title{
Chemotherapeutic targets in osteosarcoma - insights from synchrotron-microFTIR and quasi-elastic neutron scattering
}

\author{
Maria Paula M. Marques, Ana L.M. Batista de Carvalho, \\ Adriana P. Mamede, Inês P.Santos, Victoria García Sakai, \\ Asha Dopplapudi, Gianfelice Cinque, Magda Wolna, \\ Peter Gardner and Luís A.E. Batista de Carvalho
}

\section{Published version information}

Citation: M. P. M. Marques et al. "Chemotherapeutic targets in osteosarcoma insights from synchrotron-microFTIR and quasi-elastic neutron scattering." Journal of Physical Chemistry B, vol. 123, no. 32 (2019): 6968-6979.

DOI: $10.1021 / a c s . j p c b .9 b 05596$

This document is the unedited author's version of a Submitted Work that was subsequently accepted for publication in Journal of Physical Chemistry B, (02019 American Chemical Society after peer review. To access the final edited and published work see DOI above.

Please cite only the published version using the reference above. This is the citation assigned by the publisher at the time of issuing the AAM. Please check the publisher's website for any updates. 
Subscriber access provided by The Chadwick \&amp; RAL Libraries

\section{B: Biophysics; Physical Chemistry of Biological Systems and Biomolecules}

\section{Chemotherapeutic Targets in Osteosarcoma - Insights from Synchrotron-MicroFTIR and Quasi-Elastic Neutron Scattering}

Maria Paula M. Marques, Ana L.M. Batista de Carvalho, Adriana P. Mamede, Inês P. Santos, Victoria GarcíaSakai, Asha Dopplapudi, Gianfelice Cinque, Magda Wolna, Peter Gardner, and Luis A. E. Batista de Carvalho

J. Phys. Chem. B, Just Accepted Manuscript • DOI: 10.1021/acs.jpcb.9b05596 • Publication Date (Web): 24 Jul 2019

Downloaded from pubs.acs.org on August 6, 2019

\section{Just Accepted}

"Just Accepted" manuscripts have been peer-reviewed and accepted for publication. They are posted online prior to technical editing, formatting for publication and author proofing. The American Chemical Society provides "Just Accepted" as a service to the research community to expedite the dissemination of scientific material as soon as possible after acceptance. "Just Accepted" manuscripts appear in full in PDF format accompanied by an HTML abstract. "Just Accepted" manuscripts have been fully peer reviewed, but should not be considered the official version of record. They are citable by the Digital Object Identifier (DOI@). "Just Accepted" is an optional service offered to authors. Therefore, the "Just Accepted" Web site may not include all articles that will be published in the journal. After a manuscript is technically edited and formatted, it will be removed from the "Just Accepted" Web site and published as an ASAP article. Note that technical editing may introduce minor changes to the manuscript text and/or graphics which could affect content, and all legal disclaimers and ethical guidelines that apply to the journal pertain. ACS cannot be held responsible for errors or consequences arising from the use of information contained in these "Just Accepted" manuscripts. 


\title{
Chemotherapeutic Targets in Osteosarcoma -
}

\section{Insights from Synchrotron-MicroFTIR and Quasi-}

\section{Elastic Neutron Scattering}

\author{
Maria Paula M. Marques ${ }^{a, b}$, Ana L.M. Batista de Carvalho ${ }^{a *}$, Adriana P. Mamede ${ }^{a}$, Inês P. \\ Santos $^{a}$, Victoria Garcia Sakai, , Asha Dopplapudic, Gianfelice Cinque ${ }^{d}$, Magda Wolna ${ }^{d}$, Peter \\ Gardner $^{e}$ and Luís A.E. Batista de Carvalho ${ }^{a}$ \\ a “Química-Física Molecular”, Department of Chemistry, University of Coimbra, 3004-535 Coimbra, Portugal \\ b Department of Life Sciences, University of Coimbra, 3000-456 Coimbra, Portugal \\ c ISIS Facility, STFC Rutherford Appleton Laboratory, Chilton, Didcot, Oxfordshire OX11 0QX, UK \\ d Diamond Light Source, Harwell Science and Innovation Campus, Chilton, Didcot, Oxfordshire OX11 0DE, UK \\ e Manchester Institute of Biotechnology, University of Manchester, Manchester, M1 7DN, UK
}

\begin{abstract}
This study aimed at the development of improved drugs against human osteosarcoma, which is the most common primary bone tumor in children and teenagers with a low prognosis available treatment. New insights into the impact of an unconventional $\operatorname{Pd}(\mathrm{II})$ anticancer agent on human osteosarcoma cells were obtained by synchrotron-based infrared microspectroscopy (SR-microFTIR) and quasi-elastic neutron scattering (QENS) experiments from its effect on the cellular metabolism to its influence on intracellular water which can be regarded as a potential secondary pharmacological target. Specific infrared biomarkers of drug
\end{abstract}


action were identified, enabling a molecular-level description of variations in cellular biochemistry upon drug exposure. The main changes were detected on the protein and lipid cellular components, namely on the ration of unsaturated-to-saturated fatty acids. QENS revealed a reduced water mobility within the cytoplasm for drug-treated cells, coupled to a disruption of the hydration layers of biomolecules. Additionally, the chemical and dynamical profiles of osteosarcoma cells were compared to metastatic breast cancer, revealing distinct dissimilarities that may influence drug activity.

\section{INTRODUCTION}

Cancer is a growing worldwide concern, being expected to rise up to 22 million cases per year within the next two decades. Osteosarcoma, in particular, is a very aggressive type of cancer and the most common bone malignancy, with a high incidence in children and adolescents. ${ }^{1}$ Due to its poor prognosis regarding metastatic disease ( survival $<20 \%$ ), ${ }^{2}$ new and effective anticancer agents are a pressing social and medical need, aiming at killing neoplastic cells with minimal damage on healthy tissue. Minor progress has been made in osteosarcoma therapy in the last 30 years, the MAP (methotrexate, doxorubicin (adryamicin) and cisplatin) multidrug regime being presently the treatment of choice. ${ }^{3,4}$ However, a satisfactory response to this primary chemotherapy has still not been achieved, and severe toxicity of the administered drugs is a limiting factor (namely cisplatin's nephrotoxicity, doxorubicin's cardiotoxicity, and methotrexate's nephrotoxicity and myelosuppression). ${ }^{5}$ A phase III clinical trial is currently underway - the European and American Osteosarcoma Study (EURAMOS-1) - with a view to increase the survival rate of patients with osteosarcoma. The addition of novel compounds to the standard MAP scheme is one of the proposed strategies to enhance chemotherapeutic efficacy. 
Polynuclear Pt(II) and Pd(II) chelates with alkylpolyamine ligands, synthetized and extensively studied by the team in the last few years, ${ }^{6-19}$ have been shown to act as antitumor agents against metastatic breast cancer ${ }^{11,13,15,16}$ and osteosarcoma. ${ }^{18}$ Their cytotoxicity is mediated by covalent binding of the metal centers to DNA purines, yielding intra- and interstrand adducts not available to conventional mononuclear Pt-compounds and leading to an enhanced therapeutic effect. ${ }^{17,20-23}$ These drug-DNA adducts are formed upon drug activation, through hydrolysis of the leaving (chloride) ligands and aquation, followed by uptake into the nucleus and binding to DNA. The treatment outcome, however, depends on the ability to accurately monitor and understand the organism's response to the drugs, at the cellular and subcellular levels. Accordingly, these compounds have been investigated by the authors using vibrational spectroscopy - both neutron and optical methods, including infrared with synchrotron radiation, which are extremely suitable and non-destructive tools for assessing drug's bioavailability, biodistribution and metabolic impact, that are pivotal informations for a rational drug design..$^{8-10,12,14,16,17,24}$ Here this study was extended by making use of two other physico-chemical experimental probes to monitor the anticancer activity of a promising $\mathrm{Pd}(\mathrm{II})$ agent $\left(\mathrm{Pd}_{2} \mathrm{Spm}\right.$, Spm=spermine $\left.=\mathrm{H}_{2} \mathrm{~N}\left(\mathrm{CH}_{2}\right)_{3} \mathrm{NH}\left(\mathrm{CH}_{2}\right)_{4} \mathrm{NH}\left(\mathrm{CH}_{2}\right)_{3} \mathrm{NH}_{2}\right)$ towards human osteosarcoma cells, by coupling synchrotron radiation-Fourier Transform Infrared microspectroscopy (SR-microFTIR) and quasi-elastic neutron scattering (QENS) experiments.

Apart from the recognized high sensitivity and selectivity typical of FTIR spectroscopy, able to probe drug-prompted changes in cells in a rapid and non-invasive manner, ${ }^{25-30}$ synchrotron IR radiation available at the MIRIAM (Multimode InfraRed Imaging And Microspectroscopy) beamline at the Diamond Light Source ${ }^{31,32}$ delivers a stable, broadband and extremely bright IR microbeam, yielding FTIR data with an unmatched signal-to-noise ratio across the whole mid-IR 
spectrum or extended fingerprint region of interest for biomolecules. The drug-induced cellular biochemical changes as well as the cell's response to the chemotherapeutic insult can thus be revealed, at a molecular level, with high spatial and spectral accuracy.

Quasi-elastic neutron scattering, in turn, is a particularly suitable technique for interrogating the dynamical profile of water - translational and rotational diffusion processes - at the nano- to picosecond timescale (ca. 10-9-10-13 s) and atomic length scales (1 to $30 \AA$, corresponding to inter- and intramolecular distances, e.g. H-bonding) ${ }^{33}$ yielding results not achievable by any other method. Since water is present throughout the cells, QENS measurements help determine whether its dynamical behavior may be disturbed by the presence of an external entity such as a drug and provide additional insights to the mechanism for this interaction. ${ }^{17}$ Apart from a few QENS experiments carried out on water dynamics in red blood cells and bacteria, ${ }^{33-38}$ the influence of a drug on intracellular media was reported for the first time by the authors for drug-exposed human breast cancer cells ${ }^{17}$ and DNA. ${ }^{24}$ Cisplatin, $\mathrm{Pt}_{2} \mathrm{Spm}$ and $\mathrm{Pd}_{2} \mathrm{Spm}$ were shown to have a clear concentration- and drug-dependent effect on the cytomatrix, as well as on DNA's hydration shell. Hence, apart from the direct cytotoxic effect via DNA damage (the primary pharmacological target of this type of metal-based agents), drug-elicited impairment of cell growth/viability may also be mediated by variations in cytoplasmic and hydration water which impact on cellular function (secondary chemotherapeutic target).

Actually, water supports vital biochemical processes in a living organism, influencing key cellular functions such as protein stability and folding, membrane properties, enzyme catalysis, DNA packaging, molecular recognition and intracellular signaling. ${ }^{37,39-42}$ Self-association through hydrogen bonding is a particularly important characteristic of water that determines its properties, and is constantly changing as a consequence of motions of the individual water molecules as well 
as to accommodate the presence of solutes within the cellular milieu (e.g. pharmacological agents). Hence, in the crowded cell cytoplasm, which contains a complex array of macromolecular structures ranging from cytoskeletal elements and organelles to small dissolved solutes, water shows unique characteristics when compared with bulk water (e.g. regarding mobility) that are critical to diffusion-limited cellular processes. ${ }^{43}$ Indeed, even subtle changes in water dynamics between and within cells could contribute to or even be the driving force for disrupting homeostasis and initiate a series of events leading to biomacromolecular disfunction that can facilitate cell growth inhibition and cell death. Understanding the biophysical status of intercellular water is thus a major scientific challenge. In the present study, QENS measurements were performed to selectively probe the motion of water molecules within the cell - intracellular water (cytoplasm) and hydration shells (organized water solvating biomolecules, e.g. proteins and DNA) - upon exposure to the tested anticancer agents.

The $\mathrm{Pd}_{2} \mathrm{Spm}$ dinuclear complex was investigated against human osteosarcoma cells (MG-63). The well known Pt(II) chemotherapy drug cisplatin (Platinol ${ }^{\circledR}$ ), a DNA-binder, ${ }^{44}$ was also measured for comparison purposes. This approach has provided complementary information on the drug's impact on cells, on two levels: (i) regarding their effect on the cellular metabolism and on the conformation of vital biomolecules (conventional pharmacological targets such as DNA and specific proteins) - delivered by SR-microFTIR; (ii) concerning their impact on water dynamics within the cell (cytoplasmic medium and protein/DNA hydration layers), which can be considered as a potential secondary drug target ${ }^{17,24}$ - yielded by QENS measurements. The data thus gathered was compared with those previously obtained: (i) by NMR metabolomic experiments in drug-treated osteosarcoma cells, ${ }^{7,}{ }^{18}$ where the biological matrix is probed in a slower timescale and gives the average metabolic profile of the system at defined conditions as 
opposed to the specific cellular variations delivered by QENS; (ii) through a similar investigation using QENS, Raman and SR-microFTIR (mid- and far-IR regions) on human metastatic breast carcinoma cells and on DNA exposed to the same compounds, ${ }^{16,17,24}$ with a view to assess drug selectivity according to the type of tumorigenic cell line; and (iii) by synchrotron-based EXAFS (Extended X-ray Absorption Fine Structure) measurements on drug-DNA adducts, ${ }^{14}$ which led to a molecular-based interpretation of the drug-DNA interplay. Combined, the study provides a more comprehensive understanding of the pharmacodynamic profile of the $\mathrm{Pd}_{2} \mathrm{Spm}$ anticancer agent, at a molecular level, particularly regarding its cytotoxic effect both through direct interaction with its conventional target (DNA) and via an impact on intracellular water. This is an innovative approach to monitor pharmacodynamics and better interpret a drug's mechanism of action, and is expected to provide very valuable information for the rational design of metal-based anticancer agents with enhanced chemotherapeutic efficiency and minimal deleterious side effects.

\section{MATERIAL AND METHODS}

The list of chemicals, the experimental description regarding the synthesis and characterization of the $\mathrm{Pd}_{2} \mathrm{Spm}$ complex, the preparation of drug solutions and the cell culture protocol are extensively described in the Supporting Information, together with details of the SR-microFTIR and QENS data acquisition and analysis.

Sample Preparation for Synchrotron-microFTIR. Upon harvesting by trypsinization, the human osteosarcoma MG-63 cells were centrifuged and the pellet was resuspended in culture medium and seeded, at a concentration of $3 \times 10^{4}$ cells $/ \mathrm{cm}^{2}$, on $\mathrm{CaF}_{2}$ disks (Crystran UV-grade, $1 \times 13 \mathrm{~mm}$ ) previously washed with ethanol-70\%. After incubation for $48 \mathrm{~h}$ (allowing the cells to attach), each of the tested drugs (cisplatin or $\mathrm{Pd}_{2} \mathrm{Spm}$ ) was added at a 12 or $24 \mu \mathrm{M}$ concentration (according to the respective $50 \%$ cell growth inhibition values $\left(\mathrm{IC}_{50}\right)$ formerly determined by the 
authors ${ }^{18}$ ) and the cells were left to culture for a further $48 \mathrm{~h}$ (previously optimized drug incubation period $^{18}$ ). The growth medium was then removed, the cells were washed twice with $\mathrm{NaCl}-0.9 \%$ $(\mathrm{w} / \mathrm{v})$, fixed in $4 \%$ formalin (diluted in $\mathrm{NaCl}-0.9 \%$ from the commercial neutral-buffered formaldehyde solution) for $10 \mathrm{~min}^{45}$ and washed several times with pure water (to remove any residual salt). The disks were allowed to air-dry prior to spectroscopic analysis. Formalin fixation has been established as a reliable method for preserving cellular integrity, allowing an accurate comparison between cells under distinct conditions (e.g. control and drug-treated). ${ }^{28,45}$ All samples were prepared in triplicate, in a single experiment.

Preparation of Cell Pellets for QENS measurements. MG-63 cell pellets $\left(100 \mathrm{mg} / 1 \mathrm{~cm}^{3}\right.$, ca. $5 \times 10^{8}$ cells per sample), were prepared by cell harvesting (through trypsinization) followed by repeated $(2 \times)$ washing with phosphate buffer saline (PBS) and centrifugation (at $195 \times \mathrm{g}$, for 15 min). PBS was used as an isotonic medium in order to avoid water exchange from the inside to the outside of the cell (leading to cell shrinkage and death). The drugs (cisplatin or $\mathrm{Pd}_{2} \mathrm{Spm}$, at 12 and $24 \mu \mathrm{M})$ were added to the cells during their logarithmic phase of growth and left to incubate for $48 \mathrm{~h}$. In order to completely remove the extracellular water component (less than $5 \%$ ), the cell pellets were washed with deuterated PBS by resuspension $(1 \times)$ followed by centrifugation (at $195 \times \mathrm{g}$ ) for $5 \mathrm{~min}$, which was then repeated for $15 \mathrm{~min}$ (after removal of the first supernatant). ${ }^{17}$

Although these experimental conditions were previously optimized for QENS analysis of MDAMB-231 breast cancer cells, ${ }^{17}$ several centrifugation conditions (regarding speed and time) were presently tested for the MG-63 osteosarcoma cell line, $195 \times \mathrm{g}$ for $5 \mathrm{~min}$ still being the optimal settings in order to ensure that the process did not affect the integrity of the cells (verified by comparison of the corresponding QENS profiles). 
Synchrotron-microFTIR Measurements. Synchrotron-based infrared data were acquired (in the mid-IR range $650-4000 \mathrm{~cm}^{-1}$ ) at the MIRIAM B22 beamline at Diamond Light Source (United Kingdom), ${ }^{31,} 32$ in a Bruker Vertex $80 \mathrm{v}$ Fourier Transform IR interferometer (see details in the Supporting Information). SR-microFTIR measurements were performed on formalin-fixed MG63 cells, drug-free and drug-exposed, allowing access to the cellular spectral signatures in the absence and presence of the antitumor agents $\operatorname{Pd}_{2} \mathrm{Spm}$ and cisplatin.

Experiments were also carried out in drug-free MDA-MB-231 cells (human triple negative breast cancer), for comparison purposes.

QENS Measurements. QENS data were acquired at the ISIS Pulsed Neutron and Muon Source of the Rutherford Appleton Laboratory (United Kingdom), ${ }^{46}$ on the OSIRIS spectrometer ${ }^{47}$ (see details in the Supporting Information). MG-63 cell pellets were measured, both untreated and drugexposed - to cisplatin or $\operatorname{Pd}_{2} \mathrm{Spm}$, at 12 and $24 \mu \mathrm{M}$. The samples were mounted in In-sealed 0.1 mm-thick $(3 \times 5 \mathrm{~cm})$ flat Al cans (the beam size at the sample being $2.2 \times 4.4 \mathrm{~cm})$, and were oriented at $-30^{\circ}$ with respect to the incident beam. A vanadium sample (purely incoherent elastic scatterer) was also measured, to define the instrument resolution and correct for detector efficiency. Experiments were carried out at $37^{\circ} \mathrm{C}(310 \mathrm{~K})$ (physiological conditions).

\section{RESULTS AND DISCUSSION}

Synchrotron-radiation FTIR microspectroscopy and QENS (with isotope labelling) were applied for assessing the impact of $\mathrm{Pd}_{2} \mathrm{Spm}$ on human osteosarcoma cells. Detailed and complementary information was obtained on the pharmacodynamic profile of this polynuclear Pd-agent, from its effect on the cellular metabolism (provided by SR-microFTIR) to its influence on the dynamics of intracellular water (delivered by QENS) (Scheme 1). 


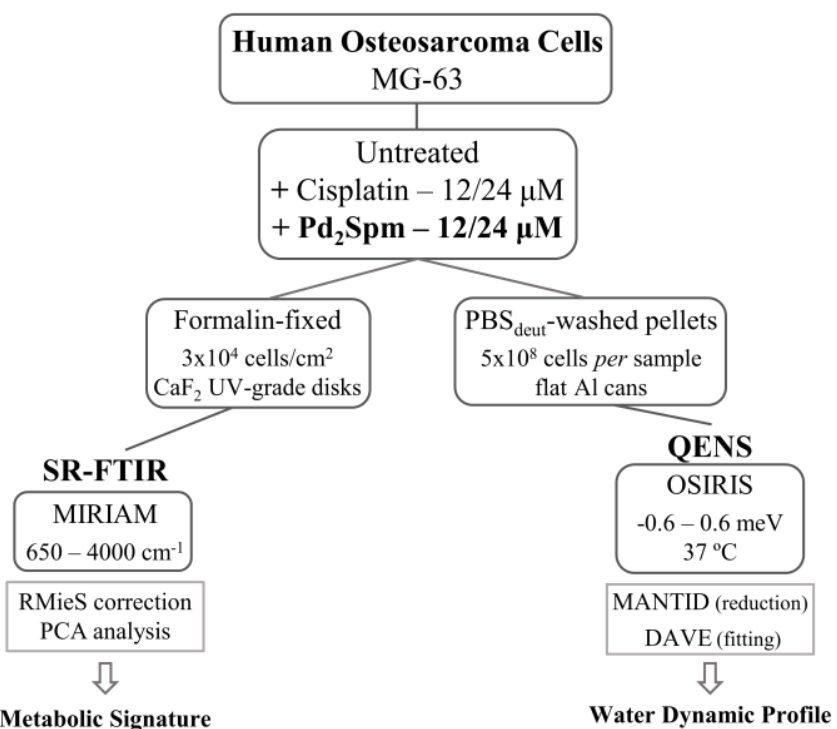

Scheme 1. Schematic representation of the present study on the drug impact on human osteosarcoma cells. (PBS - phosphate buffer saline; MIRIAM - Multimode InfraRed Imaging And Microspectroscopy; SR-microFTIR - synchrotron radiation-Fourier Transform Infrared microspectroscopy; QENS - quasi-elastic neutron scattering; RMieS - resonant Mie scattering correction; PCA - principal component analysis).

Comparison of these data with the results previously gathered (by Raman, SR-microFTIR and QENS) on the effect of the same Pd-spermine agent towards breast carcinoma cells and DNA ${ }^{16,17}$, 24 provided preliminary information on: (i) differences between the dynamical profile of intracellular water in osteosarcoma $v s$ breast cancer; (ii) drug's selectivity regarding the type of neoplastic cell line, concerning the effect on both the cytoplasmic medium and the hydration layers of vital biomolecules.

Synchrotron-microFTIR. The SR-microFTIR experiments on formalin-fixed MG-63 cells returned distinctive signatures, as a function of drug type $\left(\mathrm{Pd}_{2} \mathrm{Spm}\right.$ or cisplatin) and concentration. Infrared spectra and chemical images representing the cellular reaction to drug stimulus were 
obtained, this response being assigned to specific cellular components (e.g. proteins, lipids, DNA) with a view to identify reliable biomarkers of drug action and to better understand the drug's activity at the molecular level.

The infrared profiles of drug-exposed and drug-free osteosarcoma cells (in the mid-IR region) were generated by averaging the data measured from different cellular locations. Since $\mathrm{Pd}_{2} \mathrm{Spm}$ is suggested to be cell-cycle non-specific, similarly to its mononuclear counterpart cisplatin, the cellular impact of these drugs may be accurately obtained from the mean IR spectra presently acquired that average out any chemical differences arising from cells in different stages of the cell cycle.

Although the currently probed Pt- and Pd-agents display characteristic and intense infrared features, ${ }^{8,10,12,21}$ which were firstly detected within a biological matrix in a recent study by the authors on DNA, ${ }^{24}$ they were currently not observed within the heterogeneous cellular system probably due to the low concentrations used and to the strong interactions with cellular components such as proteins and DNA (main pharmacological target). The osteosarcoma cells showed to be sensitive to both $\mathrm{Pd}_{2} \mathrm{Spm}$ and cisplatin which elicited distinct spectral changes, for the same concentration and incubation time. A direct analysis of the infrared spectra already revealed an unambiguous drug impact. A drug-prompted influence on phospholipids was evidenced by the increase of the signal at $c a .1035 \mathrm{~cm}^{-1}$, ascribed to methylene deformations of these cellular membrane constituents. Additionally, variations in DNA's deoxyribose and guanine modes - respectively $v(\mathrm{CO})_{\text {deoxyrib }}$ at $1060 \mathrm{~cm}^{-1}$ and $v(\mathrm{CC})_{\text {ring }}$ at $1335 \mathrm{~cm}^{-1}-$ reflected a drug interaction with the nucleic acid, the Pd-agent showing a more significant impact on the purine bases (Figure $1(\mathrm{~A})$ ). In the high wavenumber region of the spectrum, drug exposure was found to elicit a clearly lower ratio of unsaturated-to-saturated lipids (fatty acids), revealed by the decreased 
intensity of the $v\left(\mathrm{CH}_{2}\right)$ signals at 2850 and $2920 \mathrm{~cm}^{-1}$ (Figure 1 (B)). Moreover, a slight increase in the $\mathrm{OH}$ stretching band from water was observed upon drug treatment, being more significant for $\mathrm{Pd}_{2} \mathrm{Spm}$-containing cells.

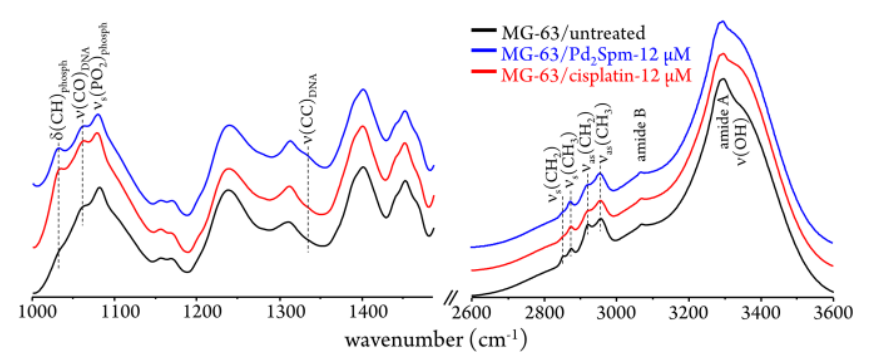

Figure 1. SR-microFTIR mean spectra (1000-1480 and 2600-3600 $\left.\mathrm{cm}^{-1}\right)$ of drug-exposed and drug-free human osteosarcoma (MG-63) formalin-fixed cells.

These spectral variations constitute an infrared signature of drug action, unique for each probed agent and experimental setup (e.g. cell type, dosage and incubation period), that reflects the drug impact on the cellular biochemical profile as well as the cell's physiological response to this stimulus. Despite the complexity of the vibrational profiles obtained for the highly crowded and heterogeneous cellular matrices under study, application of chemometric tools such as the Principal Component Analysis (PCA) enables to get an insight into the molecular basis of the detected spectral variability, leading to differentiation between spectral patterns obtained for distinct drugs or levels of drug exposure. The loading plots were matched to the respective experimental spectra, the main bands being ascribed to the different groups identified in the score maps. A good discrimination was achieved between the drug-free (controls) and drug-exposed cells, which was based on PC's characteristic of the cellular biomolecules (and not of the drugs) thus ensuring that the spectral differences are due to the drug's effect on cellular biochemistry. Figure 2 represents the loading and score plots extracted for the principal components $\mathrm{PC} 1$ and PC2 for the cisplatin- and $\mathrm{Pd}_{2} \mathrm{Spm}$-treated $(12 \mu \mathrm{M})$ versus untreated cells (in the high wavenumber 
spectral range), evidencing a good separation along PC1 and PC2, respectively. Both cisplatin and $\mathrm{Pd}_{2} \mathrm{Spm}$ were found to have a strong effect on the cellular proteins (amide A band at $c a .3300 \mathrm{~cm}^{-}$ ${ }^{1}$ ), as well as on the lipidic constituents particularly on the degree of fatty acid unsaturation reflected in the ratio between $\mathrm{CH}_{2}$ versus $\mathrm{CH}_{3}$ symmetric and antisymmetric stretching bands (2850 vs 2875 and 2920 vs $2960 \mathrm{~cm}^{-1}$, respectively). Comparing both types of drugs - mononuclear Pt-based cisplatin versus dinuclear Pd-based $\mathrm{Pd}_{2} \mathrm{Spm}$ - the loading and score plots obtained for PC1 and PC2 (in the whole spectral region probed) did not reveal a clear differentiation along PC1 $(52.9 / 32.9 \%)$ (Figure 3$)$. In fact, although there is a wider dispersion of the data from the $\mathrm{Pd}_{2} \mathrm{Spm}^{-}$ treated cells as compared to the cisplatin-exposed ones, both drugs are shown to have a predominant effect on the cellular lipids $\left(v\left(\mathrm{CH}_{2} / \mathrm{CH}_{3}\right)\right.$ bands at 2850 to $\left.2960 \mathrm{~cm}^{-1}\right)$ and on proteins. Regarding the latter, the characteristic amide I, amide A and amide B features $(v(C=O)$ peptide bond, $v(\mathrm{NH})$ and amide I/amide A Fermi resonance, respectively at ca. 1650, 3300 and $3030 \mathrm{~cm}^{-1}$ ), clearly observed in the loading plots, are known to be strongly dependent on fluctuations in intramolecular H-bonds which renders them prone to be affected by drug-biomolecule interactions.
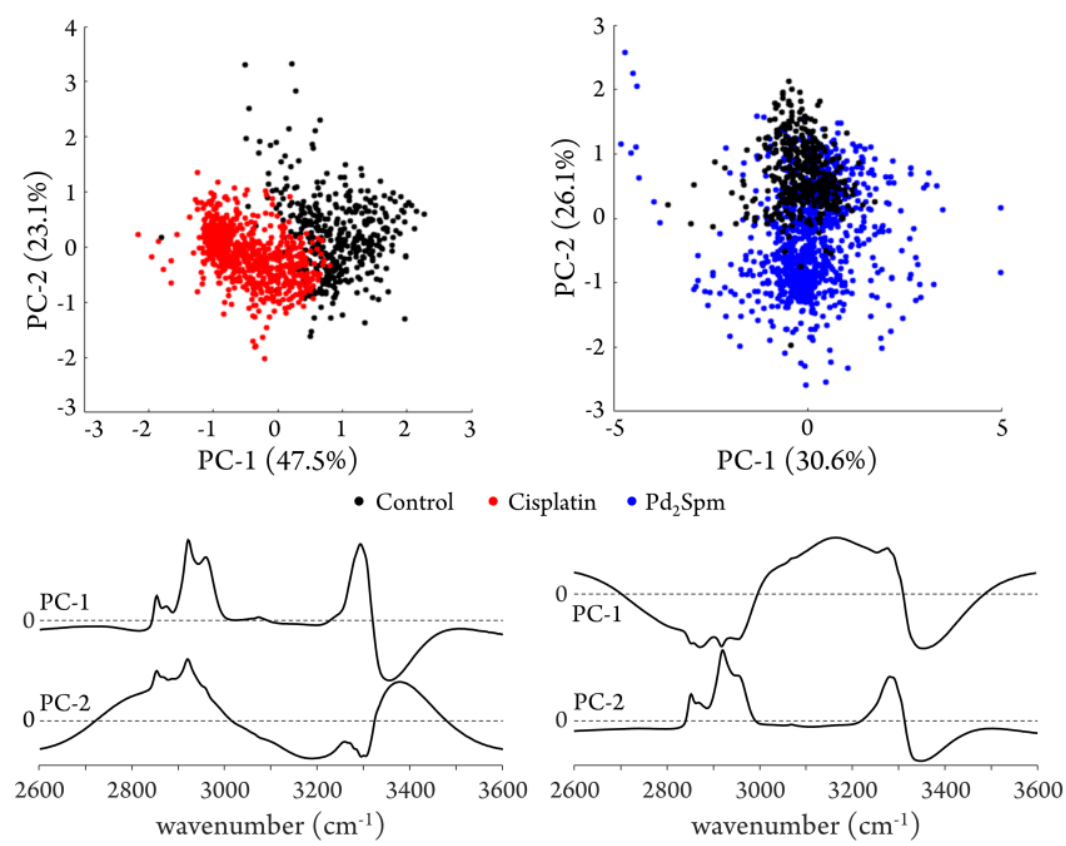
Figure 2. PCA score and loading plots of SR-microFTIR data $\left(2600-3600 \mathrm{~cm}^{-1}\right)$ for cisplatin- and $\mathrm{Pd}_{2} \mathrm{Spm}$-treated $(12 \mu \mathrm{M})$ human osteosarcoma cells (MG-63) versus the control. (For clarity the loadings are offset, the dashed horizontal lines indicating zero loading).
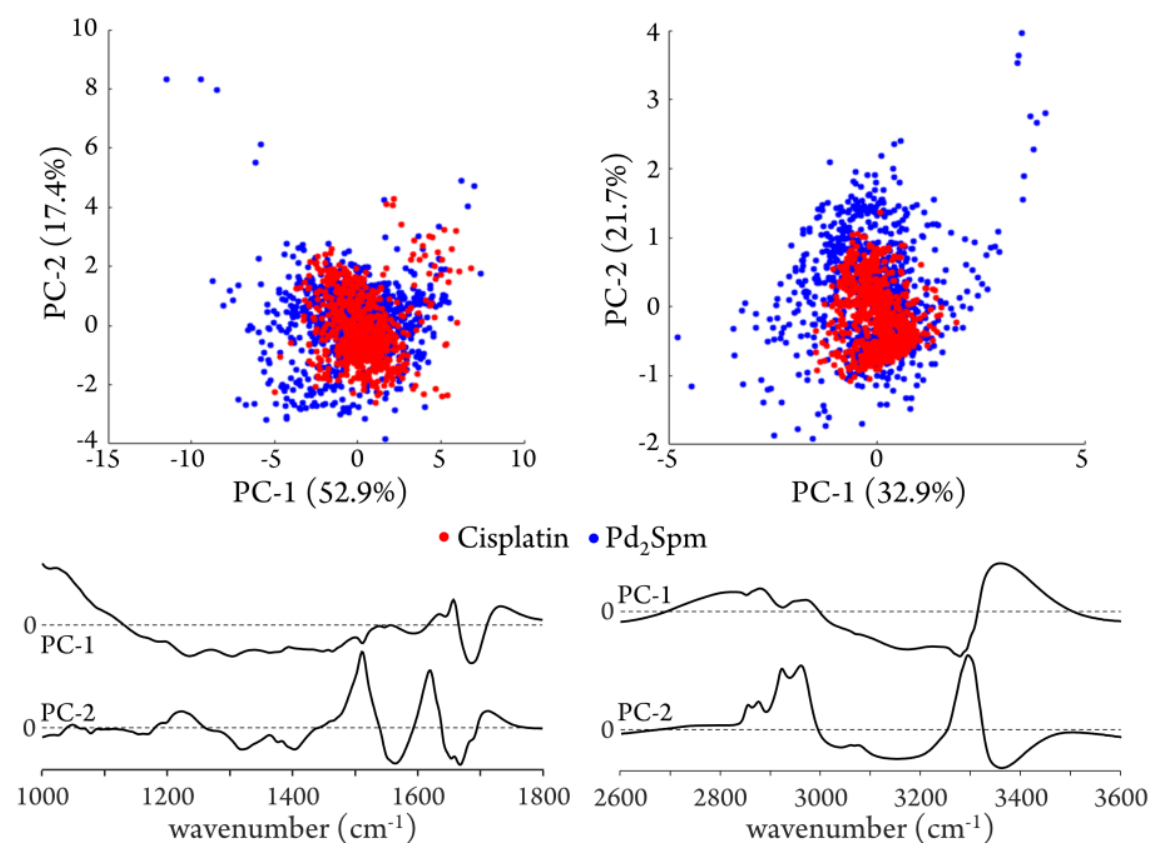

Figure 3. PCA score and loading plots of SR-microFTIR data (1000-1800 and 2600-3600 $\left.\mathrm{cm}^{-1}\right)$ for cisplatin-treated versus $\mathrm{Pd}_{2}$ Spm-treated $(12 \mu \mathrm{M})$ human osteosarcoma cells (MG-63). (For clarity the loadings are offset, the dashed horizontal lines indicating zero loading).

FTIR spectroscopic images were built for the drug-cell systems under study in order to unveil differences in biochemical composition elicited by each tested agent, with an emphasis on specific bands as potential biomarkers of drug action (Figure $4(\mathrm{~A})$ to $(\mathrm{C}))$ : (i) $v_{\mathrm{as}}\left(\mathrm{PO}_{2}\right)$ from DNA (1232$\left.1242 \mathrm{~cm}^{-1}\right)$; (ii) amide II and amide I from proteins $\left(1481-1697 \mathrm{~cm}^{-1}\right)$; and (iii) $v_{\mathrm{s}}\left(\mathrm{PO}_{2}\right)$ from the cellular phospholipids (1072-1086 $\left.\mathrm{cm}^{-1}\right)$. Both types of drug were found to have an effect on DNA, to a similar extent, which was revealed by the lower intensity of the phosphate antisymmetric stretching band in the treated versus untreated cells (Figure $4(\mathrm{~A})$ ). Figure $4(\mathrm{~B})$ shows the images generated by integrating across the amide I and II region for the control and drug-exposed samples, 
evidencing the typical protein distribution within the cell (with a high concentration in the nucleus ${ }^{48}$ ) as well as the distinct drug impact on the proteins. The most noticeable variation was observed in the $\mathrm{Pd}_{2} \mathrm{Spm}$-exposed samples, with a significantly more pronounced effect than in the cisplatin-treated cells. Regarding the phospholipidic components (mainly from the cell membrane), a drug influence was also unveiled, for both agents (Figure 4 (C)). However, the results for this particular region should be interpreted with some care, since the integrated band lies on a slope in the IR profile (Figure 1 (A)). Overall, these chemimaps evidenced a more noticeable impact of the drugs on the proteic cellular constituents, particularly evident for the Pdagent. Furthermore, the dinuclear Pd-complex was found to exert a more significant effect on osteosarcoma than the clinically used Pt-mononuclear drug cisplatin. The antitumor activities of cisplatin and $\mathrm{Pd}_{2} \mathrm{Spm}$ were previously verified to follow different pathways, ${ }^{15,17,24}$ which is to be expected since their interaction with DNA and other cellular components is likely to occur via somewhat distinct mechanisms - namely binding through more than one site per drug molecule and formation of interstrand long-range adducts in the case of the dinuclear highly flexible $\mathrm{Pd}_{2} \mathrm{Spm}$, as opposed to single drug-DNA bond yielding intrastrand short-range DNA conjugates for mononuclear cisplatin. Moreover, the nature of the metal center(s) (either $\mathrm{Pt}(\mathrm{II})$ or $\mathrm{Pd}(\mathrm{II})$ ) was formerly shown to influence cytotoxicity. ${ }^{15}$ 


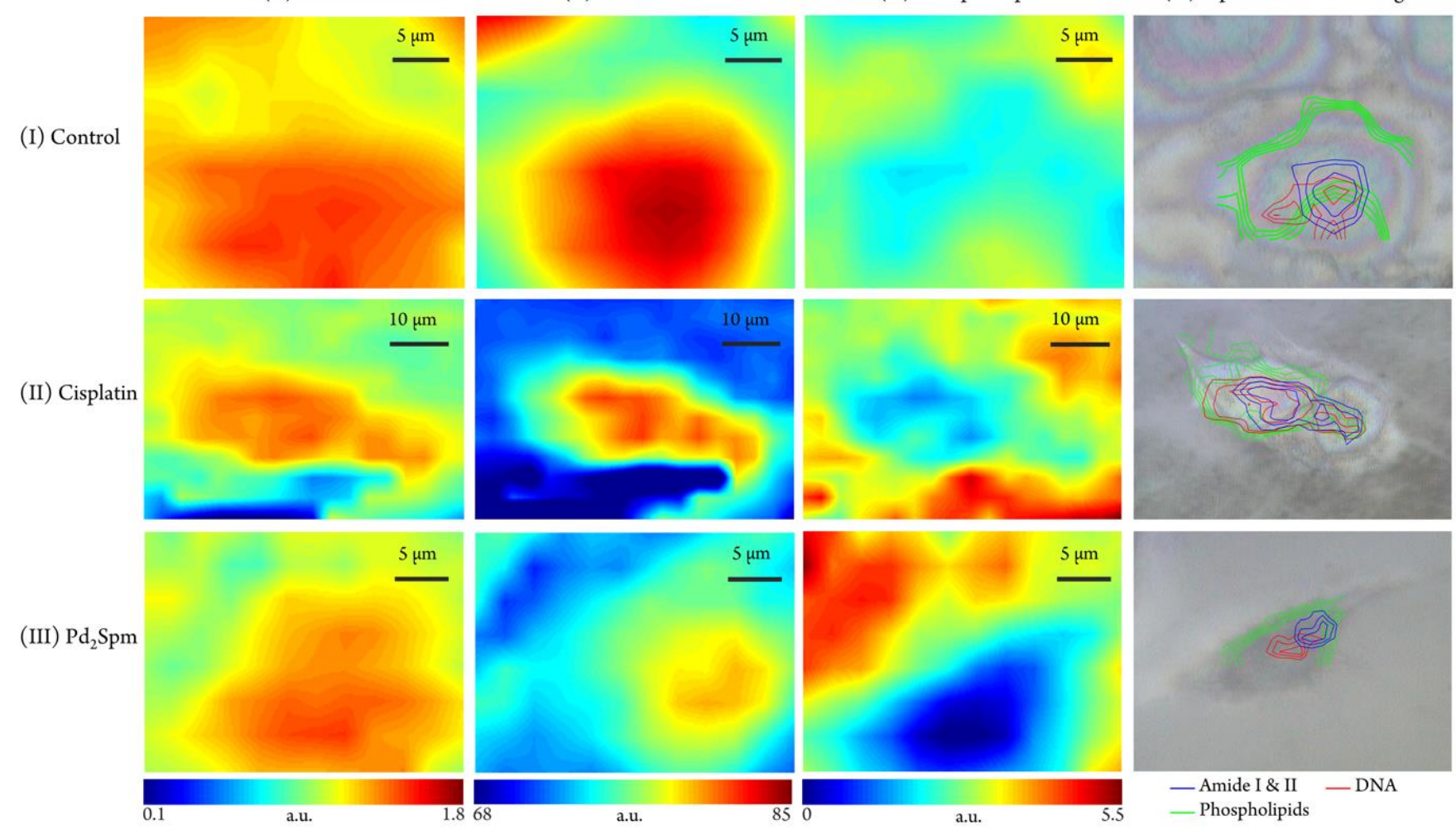

Figure 4. SR-microFTIR integrated peak area maps for untreated and drug-treated $(12 \mu \mathrm{M})$ human osteosarcoma cells (MG-63), regarding DNA (1232-1242 $\left.\mathrm{cm}^{-1}\right)(\mathrm{A})$, proteins $\left(1481-1697 \mathrm{~cm}^{-1}\right)$ (B) and lipids $\left(v_{\mathrm{s}}\left(\mathrm{PO}_{2}\right)_{\text {phospholip, }}\right.$ 1072-1086 $\left.\mathrm{cm}^{-1}\right)(\mathrm{C})$. The overlaid optical and FTIR images, for each condition, are shown in (D), the green, red and blue contours representing phospholipids, DNA and proteins, respectively.

The infrared maps obtained for drug-free and drug-exposed osteosarcoma cells were matched to the corresponding visible light images (Figure 4 (D)). This superimposed morphological and biochemical picture enabled a clear-cut visualization of the cellular distribution of the different molecular components and of the drug influence on each of them.

While the effect of $\mathrm{Pd}_{2} \mathrm{Spm}$ on the cellular proteins agrees with former studies carried out for this agent on triple-negative breast carcinoma, ${ }^{15}$ the marked changes currently observed for the lipidic constituents (including a decreased unsaturation degree) are in contrast with these earlier 
findings, the main influence of the Pd-drug in breast cancer having been found on the proteins and the DNA backbone. These results reveal drug selectivity according to cancer type, which is one of the goals of modern drug design leading to improved efficacy and minimal deleterious side-effects. Indeed, among the numerous factors that determine the effect of a chemotherapeutic agent (e.g. transport and bioavailability, access to its receptor(s), parallel reactions, cellular efflux), the physiological and histological characteristics of the biological matrix to which it is directed are of the utmost importance. Hence, a comparison between the infrared signatures of cells from human osteosarcoma (MG-63) and triple-negative breast cancer (MDA-MB-231) was currently carried out, substantial differences having been evidenced for osteosarcoma as compared to breast carcinoma (Figure 5): (i) a significantly lower unsaturation degree of the lipidic constituents reflected in the higher $\mathrm{CH}_{2} / \mathrm{CH}_{3}$ ratio represented by the bands at $2850 / 2870 \mathrm{~cm}^{-1}$ and $2920 / 2955$ $\mathrm{cm}^{-1}$, respectively ascribed to the corresponding symmetric and anti-symmetric stretching modes; (ii) a considerably decreased intensity of the signals at $c a .1030$ and $1060 \mathrm{~cm}^{-1}$ assigned to $\delta(\mathrm{CH})_{\text {phospholipids }}$ and $v(\mathrm{CO})_{\mathrm{DNA}}$, respectively; and (iii) a slightly lower amount of water $(v(\mathrm{OH})$ at ca. $\left.3350 \mathrm{~cm}^{-1}\right)$. These variances were particularly obvious regarding the enhanced intensity of the $v_{\mathrm{s}}\left(\mathrm{CH}_{2}\right)$ and $v_{\text {as }}\left(\mathrm{CH}_{2}\right)$ features (at 2850 and $2920 \mathrm{~cm}^{-1}$, respectively) for breast cancer cells (Figure 5 (A)), and were also clearly evidenced in the loading and score plots extracted for the principal components PC2 and PC3 for MG-63 versus MDA-MB-231 cells (in the high wavenumber spectral range, Figure 5 (B) and (C)). Indeed, a very good discrimination was obtained along PC2 (26.1\%), which corresponds predominantly to the $v_{\mathrm{s}}\left(\mathrm{CH}_{2}\right)$ and $v_{\text {as }}\left(\mathrm{CH}_{2}\right)$ vibrations but is also associated to the $v(\mathrm{OH})$ mode from water. These observations are in accordance with the recognized chemical variability between distinct types of cells, namely neoplastic ones, and constitutes a solid spectroscopic proof of such differences. Distinct cellular biochemical profiles 
are responsible for the particular behavior of each kind of cancer cell, namely their tumorigenic degree and metastatic ability. Activation of lipid metabolism is a hallmark of numerous types of tumors and a reliable metabolic marker of neoplasia. ${ }^{29,49}$ Additionally, increased lipid unsaturation has been reported as a requirement for cancer cell survival ${ }^{50,51}$ and the lipid composition of the cell membrane was found to be closely related to the normal-to-malignant transformation process. ${ }^{52,53}$ Hence, these cellular biochemical differences are expected to strongly determine drug activity and chemotherapeutic success.
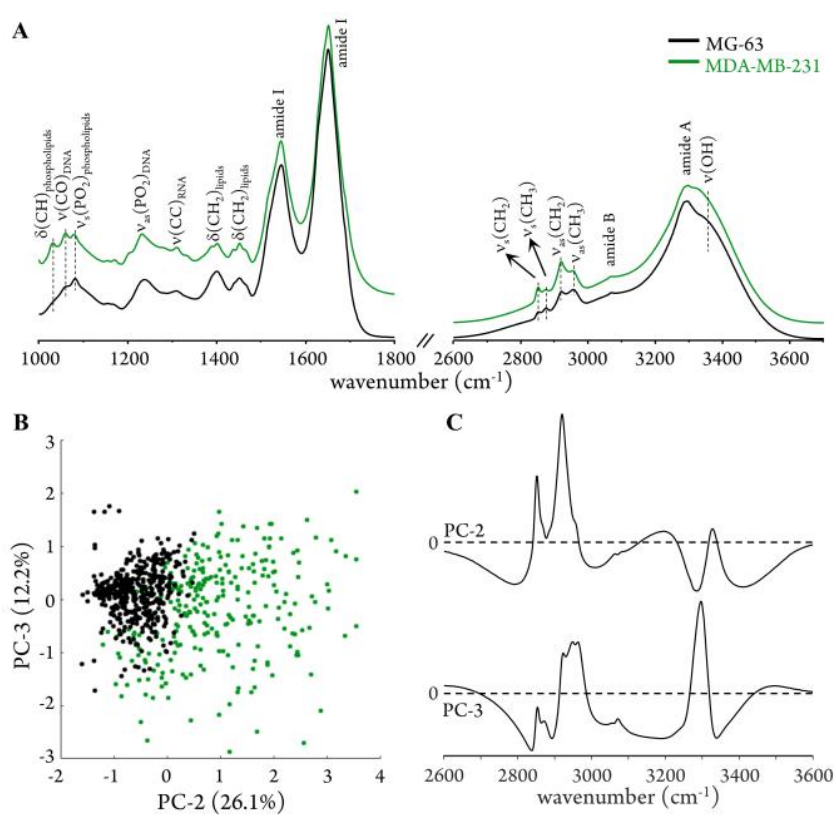

Figure 5. (A) SR-microFTIR spectra (1000-1800 and 2600-3700 $\left.\mathrm{cm}^{-1}\right)$ of human osteosarcoma (MG-63) and triple-negative breast carcinoma (MDA-MB-231) cells (formalin-fixed). (B) PCA score plots of SR-microFTIR data $\left(2600-3600 \mathrm{~cm}^{-1}\right)$ for osteosarcoma (MG-63 cells) versus breast carcinoma (MDA-MB-231 cells). (For clarity the loadings are offset, the dashed horizontal lines indicating zero loading).

Quasi-elastic Neutron Scattering. Intracellular water is a conserved structural element, displaying distinctive molecular properties (different from bulk water) that give rise to its 
particular structural and dynamical behavior, underlying its central biological function. Elucidation of water dynamics in biological systems and of its impact on activity and function is therefore of the utmost relevance in drug development, aiming at an improved understanding of the drugs' mode of action via interaction with all its possible pharmacological targets that may include the water molecules wrapping conventional receptors. The quasi-elastic measurements presently performed for the osteosarcoma cells, at the OSIRIS spectrometer, allowed us to probe the motions of water molecules within the cell - both from the cytosol (highly mobile) and the hydration layers of cellular constituents such as proteins and DNA (with a restricted flexibility ${ }^{54}$ ), as well as the local dynamics of the biomolecules. In the highly crowded and heterogeneous intracellular media, however, discrimination between these distinct dynamical processes is not straightforward.

Data was obtained for MG-63 cells, both untreated (taken as the control) and drug-treated (for $48 \mathrm{~h})$ - either with $\mathrm{Pd}_{2} \mathrm{Spm}$ or cisplatin at 12 or $24 \mu \mathrm{M}$. All QENS measurements were carried out at $37^{\circ} \mathrm{C}(310 \mathrm{~K})$, to better represent the physiological environment. Since the cells were washed with deuterated phosphate buffer saline prior to analysis, the measured signal was primarily dominated by the scattering from protons in the intracellular water, which accounts for $c a .95 \%$ of the total water within the system. Comparing data before and after drug administration allowed us to identify drug-elicited dynamical changes, that were assessed through variations in the mobility of the labile protons of the water molecules from both the cytoplasm and the hydration layers of biomolecules within the cell.

The overall dynamics of the osteosarcoma cellular system, already in the absence of drug, was found to be slower than that previously observed for the breast cancer MDA-MB-231 cells that 
display a significantly higher flexibility (Figure 6). This distinct behavior between the two neoplastic cell lines is in line with the differences in biochemical profile observed by FTIR.

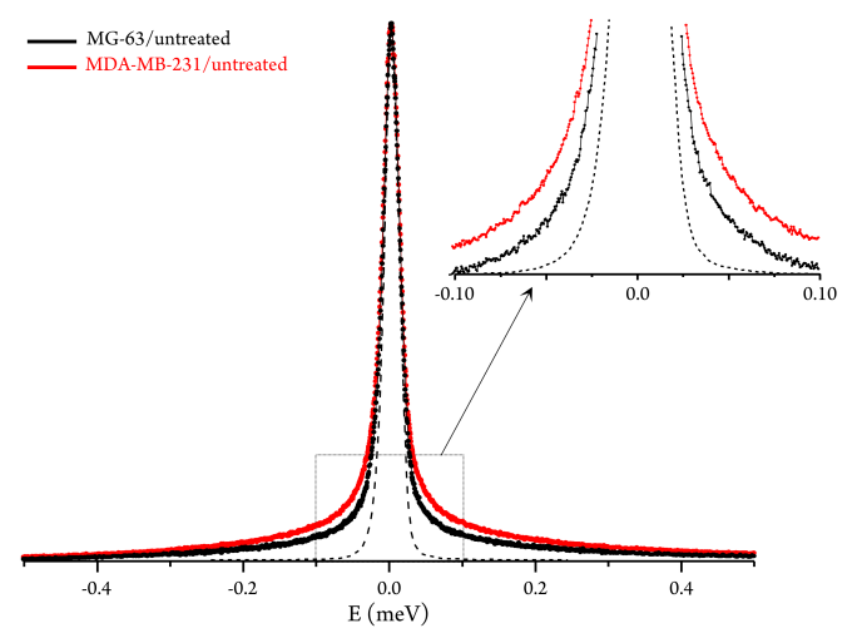

Figure 6. QENS profiles (summed over all Q values, at $310 \mathrm{~K}$ ) measured for the human cancer cells MG-63 (osteosarcoma) and MDA-MB-231 (triple-negative breast cancer ${ }^{17}$ ), in the absence of drug. (Spectra were normalized to maximum peak intensity. (The dashed line represents the instrument resolution, as measured by a standard vanadium sample).

Upon drug exposure (for $48 \mathrm{~h}$ ) a slower dynamics was observed as compared to the untreated cells, revealed by a distinctive narrowing of the QENS profiles, the impact of $\mathrm{Pd}_{2} \mathrm{Spm}$ being only slightly lower than that of cisplatin (Figure 7 (A)). This drug-elicited decreased flexibility follows the trend previously reported for the same drugs on a different human cancer cell type - triplenegative breast adenocarcinoma ${ }^{17}$ - although in this case cisplatin was shown to have a significantly higher impact as compared to the Pd-spermine complex (Figure 7 (B)). Additionally, in the concentration range under assessment the drug-elicited effect on the MG-63 cells did not display a direct dependency on concentration, $12 \mu \mathrm{M}$ being the optimal dosage for a maximum impact on water dynamics both for cisplatin and $\mathrm{Pd}_{2} \mathrm{Spm}$ (Figure 7 (C) and (D)). This is particularly evident for the former, that prompts a less pronounced effect at $24 \mu \mathrm{M}$ (Figure 7 (C)), 
while the Pd-agent yields similar QENS profiles for both concentrations (Figure 7 (D)). These results are in agreement with cytotoxicity and FTIR data obtained by the authors for cisplatin and $\operatorname{Pd}_{2} \mathrm{Spm}$ towards this osteosarcoma cell line (unpublished data), that revealed a very high cell growth inhibition already at $12 \mu \mathrm{M}$ and $c a$. $100 \%$ cell death at $24 \mu \mathrm{M}$. In turn, a distinctive concentration-dependent drug influence was previously found for breast cancer cells. ${ }^{17,18}$

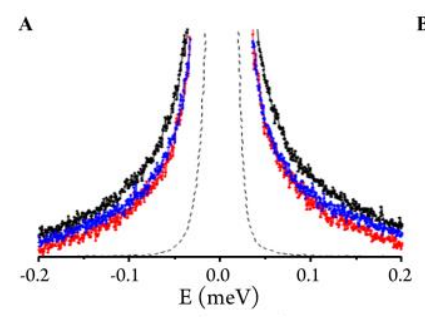

B
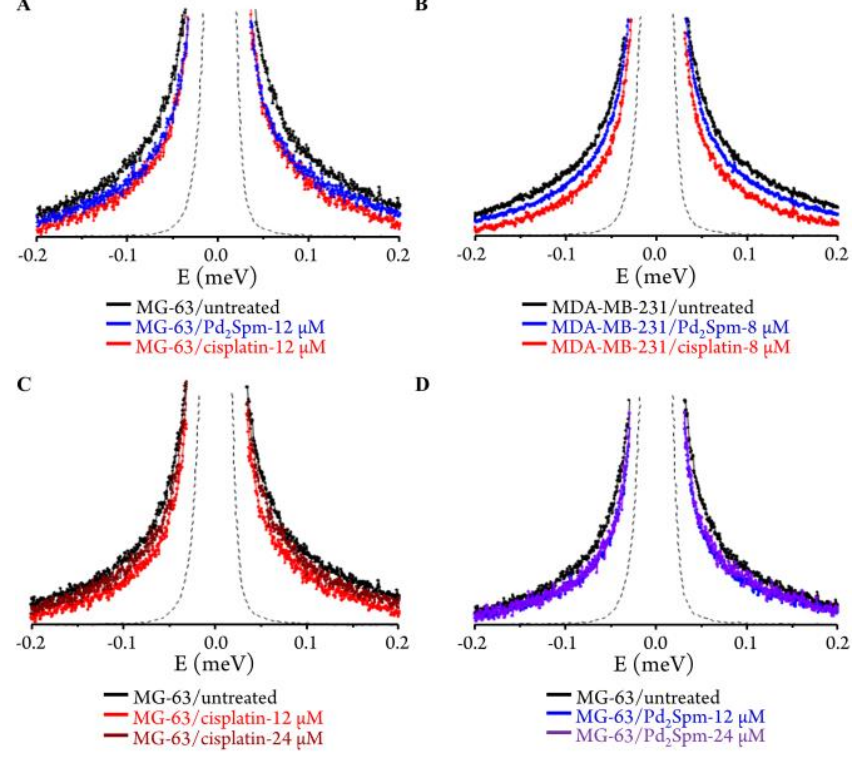

- ${ }_{\mathrm{MG}-63 / \text { untreated }}$
- ${ }_{\mathrm{MG}-63 / \mathrm{Pd}_{2} \mathrm{Spm}-12 \mu \mathrm{M}} \mathrm{Md} \mathrm{Pd}_{2} \mathrm{Spm}-24 \mu \mathrm{M}$

Figure 7. QENS profiles (for all Q values, at $310 \mathrm{~K}$ ) measured for human cancer cells (MG-63 or MDA-MB-231) with and without drug: (A) MG-63 untreated and exposed to drug-12 $\mu \mathrm{M}$. (B) MDA-MB-231 untreated and exposed to drug- $8 \mu \mathrm{M} .{ }^{17}$ (C) MG-63 untreated and exposed to cisplatin-12 and $24 \mu \mathrm{M}$. (D) MG-63 untreated and exposed to $\mathrm{Pd}_{2} \mathrm{Spm}-12$ and $24 \mu \mathrm{M}$. (Spectra were normalized to maximum peak intensity. The dashed line represents the instrument resolution, as measured by a standard vanadium sample).

Elastic scan plots (elastic intensity $v s$ temperature) allow us to gain an overview of the microscopic dynamics of a system over a wide range of temperatures, mainly used to identify dynamical transitions, but can also give an indication of structural changes (as it is the elastic intensity). Figures 8 (A) and (B) shows elastic window scans (for the whole temperature range 
probed, 20 to $310 \mathrm{~K}$ ) presently measured for the MG-63 osteosarcoma cells, in the absence and presence of the tested drugs at a $12 \mu \mathrm{M}$ concentration, showing a clear dynamical transition at $c a$. $270 \mathrm{~K}$ which in this case reflects the melting of ice within the intracellular milieu (Figure8 (A)). Drug incubation does not appear to affect the melting temperature, but the profile is somewhat different to those formerly measured for a human metastatic breast cancer cell line ${ }^{17}$ (Figure 8 (C)) where a noticeable peak is observed around $260 \mathrm{~K}$ prior to the ice structure melting. This behaviour is most likely due to the process of cold-crystallisation, which is commonly observed in heating as a transition of amorphous to crystalline ice. Since Figure 8 represents the normalised elastic intensity, an increase in crystal ice leads to an increase in the elastic intensity (as some amorphous ice molecules are rendered immobile in the ice phase) and hence to a normalised elastic intensity value larger than 1 . This is suggestive of some structural re-organization within the system, that is absent in the presence of drug and in the osteosarcoma cells. Confirmation that the drop in intensity is due to the melting of ice can be obtained from plotting the elastic intensity as a function of Q (Figure 8 (B) and (D)). Within the detector-coverage of OSIRIS, two out of the three expected Bragg peaks for hexagonal ice can be distinguished, at 1.61 and $1.70 \AA^{-1}$, corresponding to distances of $3.9 \AA$ and $3.7 \AA$, respectively. Although the formation of ice is not disrupted by the drugs, there are differences in the peak intensities (as well as in their progression with temperature, Figure S1, Supplementary Information) which may indicate variations in the extent of the ice network for the different cell lines. A full analysis of this issue is beyond the scope of the present work and would require careful neutron diffraction experiments. However, the current observations add to the suggestions from the dynamical changes measured by QENS for both types of human neoplastic cells - poorly metastatic MG-63 versus highly metastatic MDA-MB-231 and constitute further evidence of their recognized dissimilarities regarding morphological, 
biochemical and possibly functional properties. In general, invasive cancer cells display an increased plasticity relative to their non neoplastic counterparts, that has been suggested to mediate tumor aggressive progression. ${ }^{55-57}$ Actually, specific membrane and cytoskeletal proteins as well as particular tyrosine kinases, among others, have been identified as associated with enhanced cell motility and the onset of metastasis in aggressive carcinomas such as human triple-negative breast cancer $^{58,59}$ Moreover, significant differences in the tumor fatty acid profile (e.g. unsaturation degree) were identified in highly invasive cancers when compared to non-metastatic ones, which influences membrane lipid rearrangement and seems to render the cell more prone to metastatic growth. ${ }^{56,60,61}$ These noticeable chemical variations, associated to tumorigenicity and malignancy degree, may justify the distinct behavior currently observed by QENS for human osteosarcoma versus triple-negative breast cancer. Drug exposure was shown to elicit clear dynamical changes in the MG-63 osteosarcoma cells, namely a considerable increased rigidity in drug-treated samples as compared to drug-free ones. With a view to discriminate the distinct dynamical processes taking place within the heterogeneous cellular matrix, aiming at an accurate interpretation of the drug impact, the experimental QENS profiles were fitted according to the model previously optimized for breast carcinoma cells, ${ }^{17}$ using one Delta function (elastic component) convoluted with three Lorentzians (quasi-elastic contributions) (Equation 2, Supplementary Information), to represent: (i) the very slow motions of the largest organelles and cytoskeleton, and global motions of the macromolecules (slower than the longest observable time defined by the instrument resolution) assigned to the Delta function; (ii) the slow diffusion of the intracellular water (Q-dependent reorientations mediated by hydrogen bonds), both within the cytoplasm and the biomolecule's hydration layers -fitted by two narrow Lorentzians $\left(\Gamma_{\text {global }}\right)$; (iii) the fast localized motions $(\mathrm{Q}-$ independent) of the biomolecules and fast rotations of the cytosolic water molecules - ascribed to 
a broader Lorentzian $\left(\Gamma_{\text {local }}\right)$. As formerly found for breast cancer cells ${ }^{17}$, these are too complex systems to be accurately reproduced with only two Lorentzian functions ( $\Gamma_{\text {global }}$ and $\left.\Gamma_{\text {local }}\right)$, since the water molecules within the intracellular medium have distinct dynamical regimes depending on their location - in the cytoplasm (with a higher mobility, $\Gamma_{\mathrm{g} \text { lobal/cyt) }}$ or in the much more constrained hydration layers of the cellular components (e.g. proteins or DNA, $\left.\Gamma_{\text {globalhyd }}\right)$. Hence, not one but two Q-dependent Lorentzians were required to represent these motions (Figure S2).
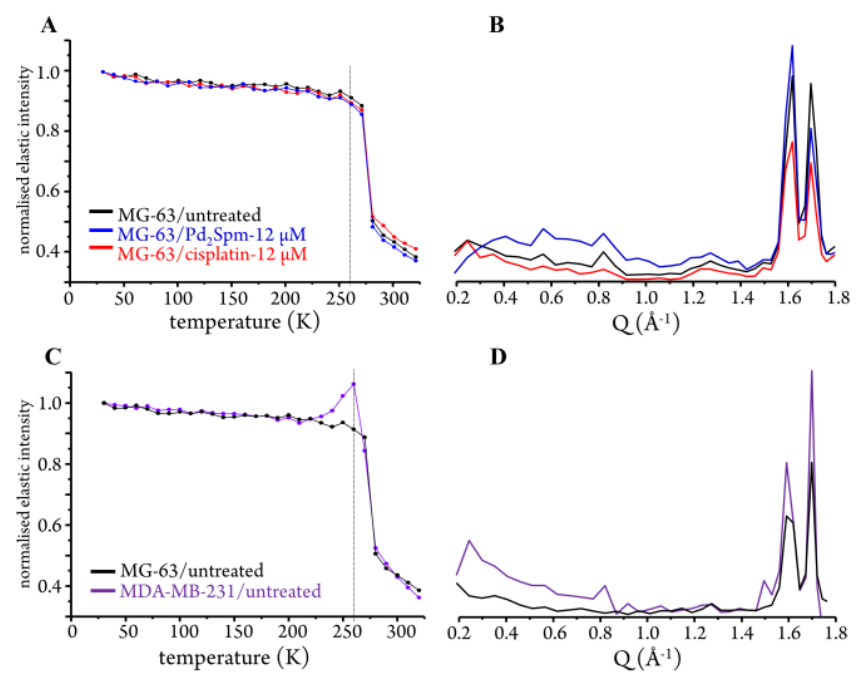

D

Figure 8. Elastic scan plots $(20-310 \mathrm{~K})$, as a function of $\mathrm{T}$ and of $\mathrm{Q}$, for the human cancer cells MG-63 (osteosarcoma) and MDA-MB-231 (triple-negative breast cancer): (A) and (B) - MG-63, untreated and after exposure to either cisplatin or $\mathrm{Pd}_{2} \mathrm{Spm}$ at $12 \mu \mathrm{M}$; (C) and (D) - MG-63 and MDA-MB-231 in the absence of drug. (Plots (B) and (D) correspond to $155 \mathrm{~K}$ and $270 \mathrm{~K}$, respectively). (The plots represent the elastic intensity integrated over the OSIRIS instrumental resolution, normalised to the elastic intensity obtained at the lowest temperature $(20 \mathrm{~K})$, which justifies the value higher than 1.0 observed for the MDA-MB-231 cells at $c a .260 \mathrm{~K}$ in Fig.8(C)).

The full widths at half-maximum were extracted from the Lorentzian functions representing each of the quasi-elastic dynamical components, and their dependence on $\mathrm{Q}^{2}$ provided information on 
the dynamical behavior of the system at the different conditions tested: the confined localized motions (broad Lorentzian) yielded a flat, Q-independent profile, while the non-localized translations of intracellular water (narrower Lorentzians) gave rise to Q-dependent functions (Figure 9), each of these motions having been found to be affected. The translational motions of intracellular water - both from the cytoplasm and hydration layers - were interpreted in the light of the known mechanism of activation and cytotoxicity of the metal-based agents currently investigated, and in accordance with a previous study on breast cancer cells: ${ }^{17}$ in the absence of drug, cytoplasmic water was found to be more flexible than hydration water as expected due to the highly organized hydration layers that strongly interact with the corresponding biopolymers, although this difference was considerably less marked than the previously measured one for breast adenocarcinoma. The translational motions of cytoplasmic water were well represented by a translational jump diffusion model ( $\Gamma_{\text {global }}$ increasing asymptotically to a plateau), with significantly constrained motions when going from untreated to drug-exposed cells at increasing dosages (12 to $24 \mu \mathrm{M}$, Figure $9(\mathrm{~A}))$. A distinct dynamical profile was revealed for hydration water (Figure $9(\mathrm{~A})$ ), that varied from a restricted Fickian diffusion in the drug-free cells (intact hydration layers) to a translational jump behavior for drug-treated cells, in which the hydration layers were prompted into a faster dynamics through a direct influence of the drug. An indirect effect is also proposed to occur, due to the biomolecules' conformational rearrangement upon drug binding (known to take place for this type of metal-based agents ${ }^{42,62}$ ) that leads to disruption of their highly structured hydration shell ${ }^{63,64}$ and to a subsequent enhanced mobility. Regarding the fast internal motions within the cell, they were shown to be independent of the scattering vector ((Figure 9 (B)) revealing localized dynamical processes. 

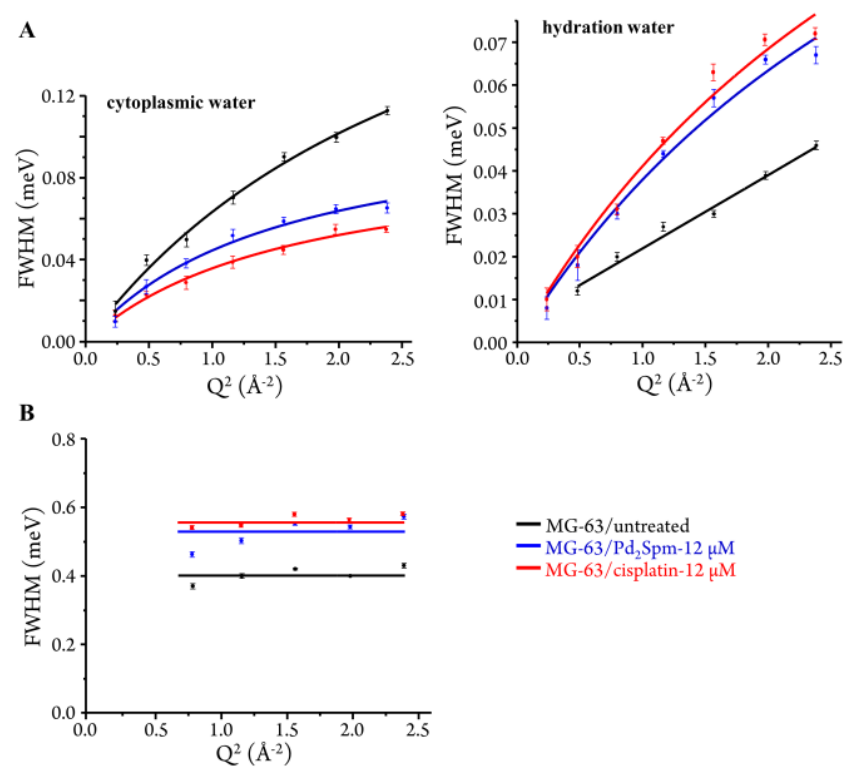

Figure 9. Variation of the full widths at half-maximum (FWHM) with $\mathrm{Q}^{2}$ for untreated and drugtreated $\left(\mathrm{Pd}_{2} \mathrm{Spm}-\right.$ and cisplatin-12 $\left.\mu \mathrm{M}\right) \mathrm{MG}-63$ cells in deuterated saline medium, at $310 \mathrm{~K}$ : (A) Lorentzian functions representing the translational motions of intracellular water - cytoplasmic medium and hydration layers. (B) Lorentzian function representing the internal localized motions within the cell.

A drug impact was therefore identified on both the cytoplasmic and hydration water, with opposed effects: a drug-prompted higher rigidity of the former coupled to an enhanced mobility of the latter. In addition, these two cellular moieties are prone to influence each other, the dynamical changes within them having an effect on the neighboring layers (cytoplasmic towards hydration and vice-versa). Furthermore, it is evident from the Q-dependent plots representing intracellular water's translational motions (Figure $9(\mathrm{~A})$ ) that the relative magnitude of the drug impact on the dynamical processes of water within the cytoplasm $v s$ the hydration layers is significantly lower than the one formerly detected for MDA-MB-231 breast cancer cells, ${ }^{17}$ which is probably due to the much lower plasticity of the intracellular milieu (cytoplasm) in the osteosarcoma MG-63 cells. 
Table 1 comprises the values of the translational diffusion coefficients $\left(\mathrm{D}_{\mathrm{T}}\right)$, translational jump times $\left(\tau_{\mathrm{T}}\right)$ and correlation times for the localized motions of the cellular macromolecules $\left(\tau_{\mathrm{L}}\right)$, at the different drug concentrations tested (at $310 \mathrm{~K}$ ), obtained from the dynamical model considered for each case. These results reflect the effect of the tested Pt- and Pd-agents on intracellular water's dynamical behavior. For the dynamical processes associated to cytoplasmic water $\left(\Gamma_{\text {global/cyt }}\right)$ a decreased mobility upon drug exposure was unveiled, reflected in lower D values and higher $\tau^{\prime}$ s: $\mathrm{D}_{\mathrm{T}}^{310}=1.28 \pm 0.009 \times 10^{-5}$ vs $1.12 \pm 0.013 \times 10^{-5}$ and $0.88 \pm 0.008 \times 10^{-5} \mathrm{~cm}^{2} \mathrm{~s}^{-1}$ and $\tau_{\mathrm{T}}=2.54 \pm 0.34$ vs $5.81 \pm 0.66$ and $6.91 \pm 0.65 \mathrm{ps}$, for untreated $v s \mathrm{Pd}_{2} \mathrm{Spm}-$ and cisplatin-12 $\mu \mathrm{M}$ treated cells, respectively. Cisplatin led to a slightly stronger effect than $\mathrm{Pd}_{2} \mathrm{Spm}$ (mainly at $12 \mu \mathrm{M}$ ). In addition, for this mononuclear Pt-agent a concentration increase from 12 to $24 \mu \mathrm{M}$ was found to have a minor influence on water dynamics (as evidenced by the corresponding QENS profiles). This drug impact presently measured for osteosarcoma is less pronounced than the one formerly obtained for the intracellular milieu (cytoplasmic water) in triple-negative breast cancer cells (MDA-MB$231)^{17}$ : ca. $30 \%$ vs $80 \%$ reduced mobility, respectively. This is probably related to the significantly lower flexibility of the osteosarcoma cells as compared to metastatic breast cancer $\left(\tau_{\mathrm{T}}=2.54\right.$ vs 1 ps, respectively). For the water molecules within hydration layers $\left(\Gamma_{\text {global/hyd }}\right)$, a drug-triggered increased flexibility ( $c a$. 4-fold) was identified: $\mathrm{D}_{\mathrm{T}}^{310}=0.17 \pm 0.0006 \times 10^{-5}$ vs $0.72 \pm 0.008 \times 10^{-5}$ and $0.78 \pm 0.01 \times 10^{-5} \mathrm{~cm}^{2} \mathrm{~s}^{-1}$ for untreated $v s \mathrm{Pd}_{2} \mathrm{Spm}$ - and cisplatin-12 $\mu \mathrm{M}$ treated cells. Although significant, the drug impact on hydration water in osteosarcoma cells was not as dramatic as the one observed for breast cancer. ${ }^{17}$ Regarding the localized motions $\left(\Gamma_{\text {local }}\right)$ of the high molecular weight cellular components (biomolecules, membranes), an enhanced mobility was found in the drug-treated cells, corresponding to lower $\tau$ values: $\tau_{\mathrm{T}}=2.50 \pm 0.002 \times 10^{-5}$ vs $1.82 \pm 0.02 \times 10^{-5}$ and $1.81 \pm 0.005 \times 10^{-5} \mathrm{~cm}^{2} \mathrm{~s}^{-1}$ for untreated $v s \mathrm{Pd}_{2} \mathrm{Spm}$ and cisplatin-12 $\mu \mathrm{M}$ treated cells, respectively. 
Table 1. Translational diffusion coefficients $\left(\mathrm{D}_{\mathrm{T}}\right)$ and relaxation times $\left(\tau_{T}, \tau_{\mathrm{L}}\right)$ of water for untreated and drug-treated MG-63 cells (at $310 \mathrm{~K}$ ), corresponding to the slow (global translational) and fast (localized rotational) dynamical processes within these systems (represented by $\Gamma_{\text {global/cyt, }}$ $\Gamma_{\text {global/hyd }}$ and $\Gamma_{\text {local}}$, respectively).

\begin{tabular}{|c|c|c|c|c|c|}
\hline \multirow[t]{2}{*}{ sample } & \multicolumn{2}{|l|}{$\Gamma_{\text {global/cyt }}$} & \multicolumn{2}{|l|}{$\Gamma_{\text {global/hyd }}$} & \multirow{2}{*}{$\begin{array}{l}\Gamma_{\text {local }} \\
\tau_{\mathrm{L}}(\mathrm{ps})\end{array}$} \\
\hline & $\mathrm{D}_{\mathrm{T}}\left(\mathrm{x} 10^{-5} \mathrm{~cm}^{2} \mathrm{~s}^{-1}\right)$ & $\tau_{\mathrm{T}}(\mathrm{ps})$ & $\mathrm{D}_{\mathrm{T}}\left(\mathrm{x} 10^{-5} \mathrm{~cm}^{2} \mathrm{~s}^{-1}\right)$ & $\tau_{\mathrm{T}}(\mathrm{ps})$ & \\
\hline MG-63 & $1.28 \pm 0.01$ & $2.54 \pm 0.34$ & ${ }^{\#} 0.17 \pm 0.00$ & - & $2.50 \pm 0.01$ \\
\hline MG-63+Pd $2 \mathrm{Spm}^{-12 \mu \mathrm{M}}$ & $1.12 \pm 0.01$ & $5.81 \pm 0.66$ & $0.72 \pm 0.01$ & $3.43 \pm 0.88$ & $1.82 \pm 0.02$ \\
\hline $\mathrm{MG}-63+\mathrm{Pd}_{2} \mathrm{Spm}_{-24 \mu \mathrm{M}}$ & $1.00 \pm 0.01$ & $6.72 \pm 0.29$ & $0.72 \pm 0.01$ & $3.25 \pm 0.73$ & $1.88 \pm 0.01$ \\
\hline MG-63+cisplatin-12 $\mu \mathrm{M}$ & $0.88 \pm 0.01$ & $6.91 \pm 0.65$ & $0.78 \pm 0.01$ & $3.23 \pm 0.87$ & $1.81 \pm 0.01$ \\
\hline MG-63+cisplatin-24 $\mu \mathrm{M}$ & $0.89 \pm 0.01$ & $7.02 \pm 0.67$ & $0.82 \pm 0.01$ & $3.48 \pm 0.96$ & $1.91 \pm 0.01$ \\
\hline
\end{tabular}

${ }^{\#}$ Fickian behavior $\left(\Gamma=2 \mathrm{DQ}^{2}\right)$.

Overall, the dinuclear Pd-agent elicited a stronger effect on osteosarcoma as compared to the formerly studied mammary adenocarcinoma, for which cisplatin prompted a significantly higher effect. Additionally, $12 \mu \mathrm{M}$ was clearly unveiled as an optimal drug dosage (under the experimental conditions tested) for both cisplatin and $\mathrm{Pd}_{2} \mathrm{Spm}$. Furthermore, the translational diffusion coefficient currently obtained for cytoplasmic water in drug-free osteosarcoma cells $\left(\mathrm{D}_{\mathrm{T}}{ }^{310}=1.28 \times 10^{-5} \mathrm{~cm}^{2} \mathrm{~s}^{-1}\right)$ was found to be greatly reduced from that of pure water $\left(\mathrm{D}_{\mathrm{T}}{ }^{298}=2.3 \times 10^{-5}\right.$ $\mathrm{cm}^{2} \mathrm{~s}^{-1}{ }^{65}$ ), corroborating the low plasticity of this type of cells, while the $\mathrm{D}_{\mathrm{T}}$ values measured in drug-exposed cells are similar to the one reported for extreme halophiles, in which the high salt concentration leads to a marked reduced mobility of intracellular water $\left(\mathrm{D}_{\mathrm{T}}{ }^{285}=1.29 \times 10^{-5} \mathrm{~cm}^{2} \mathrm{~s}^{-1} \mathrm{vs}\right.$ $\mathrm{D}_{\mathrm{T}}^{310}=1.12 \times 10^{-5} \mathrm{~cm}^{2} \mathrm{~s}^{-1}$, respectively for halophiles ${ }^{38}$ and $\mathrm{Pd}_{2} \mathrm{Spm}-12 \mu \mathrm{M}$ treated osteosarcoma). 
The results currently obtained coupled to those previously reported for human metastatic breast cancer cells ${ }^{17}$ are indicative of a selective drug impact on intracellular water dynamics, both regarding cell type (breast cancer vs osteosarcoma) and drug type (dinuclear $\mathrm{Pd}_{2} \mathrm{Spm}$ vs mononuclear Pt-based cisplatin). This is in accordance with former results obtained by the team: (i) cytotoxicity assays showing osteosarcoma cells as significantly more sensitive to the Pd-agent than to cisplatin $\left(\mathrm{IC}_{50} 12\right.$ vs $24 \mu \mathrm{M}$, respectively ${ }^{18}$ ); (ii) vibrational microspectroscopy ${ }^{16}$ and $\mathrm{NMR}$ experiments $^{19}$ on the drug's impact on cellular metabolism, revealing distinct mechanisms of action for mononuclear Pt-based cisplatin as compared to polynuclear $\mathrm{Pd}_{2} \mathrm{Spm}$. The data obtained for both types of neoplastic cells, in tandem with the results recently reported by the authors on the drug-DNA interaction, ${ }^{24}$ allow to attain a more accurate molecular interpretation of the pharmacodynamics (effect on the pharmacological target) of this type of metal-based anticancer drugs.

\section{CONCLUSIONS}

The effect of a polyamine dinuclear $\mathrm{Pd}(\mathrm{II})$ drug $\left(\mathrm{Pd}_{2} \mathrm{Spm}\right)$ on human osteosarcoma cells (MG63) was studied, using SR-microFTIR and QENS to probe the cellular biochemical profile and intracellular water dynamics, respectively. This multidisciplinary approach provided accurate and unique information on the cellular matrix in the absence and presence of the antineoplastic agent (at different concentrations), and a comparison was made to the conventional drug cisplatin. This work builds on the success of previous similar experiments on human triple-negative breast cancer cells ${ }^{16,17}$ and DNA, ${ }^{24}$ that evidenced a drug impact on distinct cellular constituents (DNA, proteins and lipids) and a concentration-dependent effect on water molecules from the cytomatrix and the hydration layers of biomolecules. 
Distinctive spectral signatures were obtained by synchrotron-based infrared microspectroscopy, as a function of drug type and concentration, with specific biomarkers of drug action being identified (representative of major cellular constituents) that enabled a molecular-level description of variations in cellular biochemistry upon drug incubation. The main drug impact was found to be on the lipidic and protein cellular components, with $\mathrm{Pd}_{2} \mathrm{Spm}$ exerting a stronger effect on the MG-63 osteosarcoma cells than the clinical Pt-drug cisplatin. In particular, a drug-prompted influence was observed on the membrane phospholipids coupled to a markedly decreased ratio of unsaturated-to-saturated fatty acids. Coupling this information to the data previously obtained for human metastatic breast adenocarcinoma, ${ }^{16,17}$ it was possible to compare the $\mathrm{Pd}_{2} \mathrm{Spm}^{\prime}$ s activity towards both types of neoplastic cell lines thus assessing both effectiveness and selectivity: different biochemical effects were measured, particularly towards the lipids. Interestingly, distinct biochemical profiles were unveiled for these two cell lines, based on their infrared signatures, namely regarding the unsaturation degree of fatty acids.

The quasi-elastic neutron scattering experiments performed on the drug-incubated osteosarcoma cells revealed a marked impact on the intracellular milieu - cytoplasmic and hydration water separately. While the former showed a restrained dynamics upon drug exposure, the hydration shells were prompted into a more mobile state, in good agreement with the data previously gathered for breast cancer. ${ }^{17}$ In addition, $\mathrm{Pd}_{2} \mathrm{Spm}$ was found to have a higher impact on intracellular water for osteosarcoma relative to breast carcinoma, for an optimal dosage of $12 \mu \mathrm{M}$. These results demonstrate the noticeable effect of metal-based antitumor agents on the dynamical behavior of water molecules, supporting intracellular water as a promising novel therapeutic target apart from the conventional biochemical drug receptors (e.g. DNA, proteins). This may hopefully lead to an enhanced drug-induced cytotoxicity via the water molecules both in the intracellular 
medium and in the close vicinity of biopolymers (as previously shown for $\mathrm{DNA}^{24}$ ). Moreover, clear differences were found between the currently investigated osteosarcoma cells and the metastatic breast cancer formerly studied ${ }^{16,17}$, regarding: (i) their biochemical profile - namely the level of fatty acid unsaturation - revealed by FTIR; (ii) the dynamical behavior of intracellular water - breast cancer cells displaying a considerably higher plasticity - unveiled by QENS.

The present study benefited from the complementary information delivered by SR-microFTIR and QENS, which provide high resolution data on both the cellular biochemical profile and intracellular water dynamics upon drug administration. Furthermore, it adds to the metabolomic studies previously performed for cisplatin- and $\mathrm{Pd}_{2}$ Spm-osteosarcoma samples by NMR, ${ }^{7,} 18,19$ which probe the biological matrix on a different timescale and can only provide an average metabolic profile. Once different types of cancers display distinct biochemical profiles the impact of the currently tested agents on osteosarcoma may differ significantly from that previously measured for human metastatic breast carcinoma, such a selectivity having been verified for $\mathrm{Pd}_{2} \mathrm{Spm}$ (in agreement with the previous NMR metabolomic analysis). In fact, the present SRmicroFTIR and QENS experiments revealed different chemical and dynamical profiles for these two cancer cell lines. This is a very important information for enhancing the effectiveness of the chemotherapeutic treatment coupled to decreased deleterious side effects, and may also help to circumvent acquired resistance mechanisms.

A comprehensive and reliable set of data has provided a molecular basis of cytotoxicity for the promising anticancer agent $\mathrm{Pd}_{2} \mathrm{Spm}$ towards the very low prognosis human osteosarcoma, shedding light into its mode of action. Namely through a multistep process that leads to loss of function in vital biomolecules and ultimately to cell death: (i) direct binding to DNA (at the purine's $\mathrm{N}_{7}$ atom), that causes disruption of its native conformation and triggers biofunctional 
disability; (ii) perturbation of the nucleic acid's hydration layer, which is prompted into a faster dynamics, inducing changes in the biopolymer with consequences at the functional level; (iii) impact on intracellular water (cytosol), with an expected global effect on essential cellular components which hinder normal cellular function. This pivotal information will hopefully pave the way for the development of novel Pd/Pt-based drugs against low prognosis osteosarcoma, that mainly affects youngsters.

\section{ACKNOWLEDGEMENTS}

The authors acknowledge financial support from the Portuguese Foundation for Science and Technology - UID/MULTI/00070/2019, POCI-01-0145-FEDER-0016786 and Centro-01-0145FEDER-029956 (co-financed by COMPETE 2020, Portugal 2020 and European Community through FEDER). The STFC Rutherford Appleton Laboratory is thanked for access to the Research Complex at Harwell (cell culture laboratories) and to the neutron beam facilities (OSIRIS/RB1810012, DOI 10.5286/ISIS.E.90683153). Diamond Light Source (UK) is acknowledged for access to the B22/MIRIAM beamline (SM19692).

The authors wish to thank to Mike Pilling for his support and helpful discussions.

\section{REFERENCES}

1. Lauvrak, S. U.; Munthe, E.; Kresse, S. H.; Stratford, E. W.; Namlos, H. M.; Meza-Zepeda, L. A.; Myklebost, O., Functional characterisation of osteosarcoma cell lines and identification of mRNAs and miRNAs associated with aggressive cancer phenotypes. Br J Cancer 2013, 109 (8), 2228-2236. 
2. Mirabello, L.; Troisi, R. J.; Savage, S. A., Osteosarcoma incidence and survival rates from 1973 to 2004: data from the Surveillance, Epidemiology, and End Results Program. Cancer 2009, $115(7), 1531-1543$.

3. Eilber, F.; Giuliano, A.; Eckardt, J.; Patterson, K.; Moseley, S.; Goodnight, J., Adjuvant chemotherapy for osteosarcoma: a randomized prospective trial. J Clin Oncol 1987, 5 (1), 21 26.

4. Hattinger, C. M.; Pasello, M.; Ferrari, S.; Picci, P.; Serra, M., Emerging drugs for high-grade osteosarcoma. Expert Opin Emerg Drugs 2010, 15 (4), 615-634.

5. Janeway, K. A.; Grier, H. E., Sequelae of osteosarcoma medical therapy: a review of rare acute toxicities and late effects. Lancet Oncol 2010, 11 (7), 670-678.

6. Marques, M. P.; Girao, T.; Pedroso De Lima, M. C.; Gameiro, A.; Pereira, E.; Garcia, P., Cytotoxic effects of metal complexes of biogenic polyamines. I. Platinum(II) spermidine compounds: prediction of their antitumour activity. Biochim Biophys Acta 2002, 1589 (1), 6370.

7. Duarte, I. F.; Lamego, I.; Marques, J.; Marques, M. P.; Blaise, B. J.; Gil, A. M., Nuclear magnetic resonance (NMR) study of the effect of cisplatin on the metabolic profile of MG-63 osteosarcoma cells. J Proteome Res 2010, 9 (11), 5877-5886.

8. Batista de Carvalho, L. A. E.; Marques, M. P.; Martin, C.; Parker, S. F.; Tomkinson, J., Inelastic neutron scattering study of $\mathrm{Pt}(\mathrm{II})$ complexes displaying anticancer properties. Chemphyschem 2011, 12 (7), 1334-1341.

9. Silva, T. M.; Oredsson, S.; Persson, L.; Woster, P.; Marques, M. P., Novel Pt(II) and Pd(II) complexes with polyamine analogues: synthesis and vibrational analysis. $J$ Inorg Biochem 2012, 108, 1-7. 
10. Marques, M. P.; Valero, R.; Parker, S. F.; Tomkinson, J.; Batista de Carvalho, L. A., Polymorphism in cisplatin anticancer drug. J Phys Chem B 2013, 117 (21), 6421-6529.

11. Fiuza, S. M.; Holy, J.; Batista de Carvalho, L. A.; Marques, M. P., Biologic activity of a dinuclear Pd(II)-spermine complex toward human breast cancer. Chem Biol Drug Des 2011, $77(6), 477-488$.

12. Fiuza, S. M.; Amado, A. M.; Parker, S. F.; Marques, M. P. M.; Batista de Carvalho, L. A. E., Conformational insights and vibrational study of a promising anticancer agent: the role of the ligand in $\mathrm{Pd}(\mathrm{II})-$ amine complexes. New Journal of Chemistry 2015, 39 (8), 6274-6283.

13. Silva, T. M.; Andersson, S.; Sukumaran, S. K.; Marques, M. P.; Persson, L.; Oredsson, S., Norspermidine and Novel Pd(II) and Pt(II) Polynuclear Complexes of Norspermidine as Potential Antineoplastic Agents Against Breast Cancer. Plos One 2013, 8 (2), e 55651.

14. Marques, M. P.; Gianolio, D.; Cibin, G.; Tomkinson, J.; Parker, S. F.; Valero, R.; Pedro Lopes, R.; Batista de Carvalho, L. A., A molecular view of cisplatin's mode of action: interplay with DNA bases and acquired resistance. Phys Chem Chem Phys 2015, 17 (7), 5155-5171.

15. Batista de Carvalho, A. L. M.; Medeiros, P. S.; Costa, F. M.; Ribeiro, V. P.; Sousa, J. B.; Diniz, C.; Marques, M. P., Anti-Invasive and Anti-Proliferative Synergism between Docetaxel and a Polynuclear Pd-Spermine Agent. PLoS ONE 2016, 11 (11), e0167218.

16. Batista de Carvalho, A. L. M.; Pilling, M.; Gardner, P.; Doherty, J.; Cinque, G.; Kelley, C.; Batista de Carvalho, L. A. E.; Marques, M. P., Chemotherapeutic response to cisplatinlike drugs in human breast cancer cells probed by vibrational microspectroscopy. Faraday Discussions 2016, 187, 273-298. 
17. Marques, M. P.; Batista de Carvalho, A. L.; Sakai, V. G.; Hatter, L.; Batista de Carvalho, L. A., Intracellular water - an overlooked drug target? Cisplatin impact in cancer cells probed by neutrons. Phys Chem Chem Phys 2017, 19 (4), 2702-2713.

18. Lamego, I.; Marques, M. P.; Duarte, I. F.; Martins, A. S.; Oliveira, H.; Gil, A. M., Impact of the Pd2Spermine Chelate on Osteosarcoma Metabolism: An NMR Metabolomics Study. $J$ Proteome Res 2017, 16 (4), 1773-1783.

19. Lamego, I.; Duarte, I. F.; Marques, M. P.; Gil, A. M., Metabolic markers of MG-63 osteosarcoma cell line response to doxorubicin and methotrexate treatment: comparison to cisplatin. J Proteome Res 2014, 13 (12), 6033-6045.

20. Marques, M. P. M., Platinum and Palladium Polyamine Complexes as Anticancer Agents: The Structural Factor. ISRN Spectroscopy 2013, 2013, 1-29.

21. Batista de Carvalho, A. L. M.; Parker, S. F.; Batista de Carvalho, L. A. E.; Marques, M. P. M., Novel platinum-based anticancer drug: a complete vibrational study. Acta Crystallogr C Struct Chem 2018, 74 (Pt 5), 628-634.

22. Farrell, N. P., Multi-platinum anti-cancer agents. Substitution-inert compounds for tumor selectivity and new targets. Chem Soc Rev 2015, 44 (24), 8773-8785.

23. Alam, M. N.; Huq, F., Comprehensive review on tumour active palladium compounds and structure-activity relationships. Coordination Chemistry Reviews 2016, 316, 36-67.

24. Batista de Carvalho, A. L. M.; Mamede, A. P.; Dopplapudi, A.; Garcia Sakai, V.; Doherty, J.; Frogley, M.; Cinque, G.; Gardner, P.; Gianolio, D.; Batista de Carvalho, L. A. E.; Marques, M. P. M., Anticancer drug impact on DNA - a study by neutron spectroscopy coupled with synchrotron-based FTIR and EXAFS. Phys Chem Chem Phys 2019, 21 (8), 4162-4175. 
25. Dumas, P.; Sockalingum, G. D.; Sule-Suso, J., Adding synchrotron radiation to infrared microspectroscopy: what's new in biomedical applications? Trends Biotechnol 2007, 25 (1), 40-44.

26. Bellisola, G.; Sorio, C., Infrared spectroscopy and microscopy in cancer research and diagnosis. Am J Cancer Res 2012, 2 (1), 1-21.

27. Derenne, A.; Verdonck, M.; Goormaghtigh, E., The effect of anticancer drugs on seven cell lines monitored by FTIR spectroscopy. Analyst 2012, 137 (14), 3255-3264.

28. Baker, M. J.; Trevisan, J.; Bassan, P.; Bhargava, R.; Butler, H. J.; Dorling, K. M.; Fielden, P. R.; Fogarty, S. W.; Fullwood, N. J.; Heys, K. A.; Hughes, C.; Lasch, P.; Martin-Hirsch, P. L.; Obinaju, B.; Sockalingum, G. D.; Sule-Suso, J.; Strong, R. J.; Walsh, M. J.; Wood, B. R.; Gardner, P.; Martin, F. L., Using Fourier transform IR spectroscopy to analyze biological materials. Nat Protoc 2014, 9 (8), 1771-1791.

29. Derenne, A.; Vandersleyen, O.; Goormaghtigh, E., Lipid quantification method using FTIR spectroscopy applied on cancer cell extracts. Biochim Biophys Acta 2014, 1841 (8), 12001209.

30. Mignolet, A.; Derenne, A.; Smolina, M.; Wood, B. R.; Goormaghtigh, E., FTIR spectral signature of anticancer drugs. Can drug mode of action be identified? Biochim Biophys Acta 2016, 1864 (1), 85-101.

31. Cinque, G.; Frogley, M.; Wehbe, K.; Filik, J.; Pijanka, J., Multimode InfraRed Imaging and Microspectroscopy (MIRIAM) Beamline at Diamond. Synchrotron Radiation News 2011, 24 (5), 24-33. 
32. Saha, T.; Dasari, S.; Tewari, D.; Prathap, A.; Sureshan, K. M.; Bera, A. K.; Mukherjee, A.; Talukdar, P., Hopping-Mediated Anion Transport through a Mannitol-Based Rosette Ion Channel. J Am Chem Soc 2014, 136 (40), 14128-14135.

33. Jasnin, M.; Moulin, M.; Haertlein, M.; Zaccai, G.; Tehei, M., Down to atomic-scale intracellular water dynamics. EMBO Rep 2008, 9 (6), 543-547.

34. Jasnin, M.; Moulin, M.; Haertlein, M.; Zaccai, G.; Tehei, M., In vivo measurement of internal and global macromolecular motions in Escherichia coli. Biophys $J$ 2008, 95 (2), 857864.

35. Frolich, A.; Gabel, F.; Jasnin, M.; Lehnert, U.; Oesterhelt, D.; Stadler, A. M.; Tehei, M.; Weik, M.; Wood, K.; Zaccai, G., From shell to cell: neutron scattering studies of biological water dynamics and coupling to activity. Faraday Discuss 2009, 141, 117-130.

36. Jasnin, M.; Stadler, A.; Tehei, M.; Zaccai, G., Specific cellular water dynamics observed in vivo by neutron scattering and NMR. Phys Chem Chem Phys 2010, 12 (35), 10154-10160.

37. Mamontov, E.; Chu, X. Q., Water-protein dynamic coupling and new opportunities for probing it at low to physiological temperatures in aqueous solutions. Phys Chem Chem Phys 2012, $14(33), 11573-11588$.

38. Tehei, M.; Franzetti, B.; Wood, K.; Gabel, F.; Fabiani, E.; Jasnin, M.; Zamponi, M.; Oesterhelt, D.; Zaccai, G.; Ginzburg, M.; Ginzburg, B. Z., Neutron scattering reveals extremely slow cell water in a Dead Sea organism. Proc Natl Acad Sci U S A 2007, 104 (3), 766-771.

39. Laage, D.; Elsaesser, T.; Hynes, J. T., Water Dynamics in the Hydration Shells of Biomolecules. Chem Rev 2017, 117 (16), 10694-10725. 
40. Fenimore, P. W.; Frauenfelder, H.; McMahon, B. H.; Young, R. D., Bulk-solvent and hydration-shell fluctuations, similar to alpha- and beta-fluctuations in glasses, control protein motions and functions. Proc Natl Acad Sci US A 2004, 101 (40), 14408-14413.

41. Frauenfelder, H.; Chen, G.; Berendzen, J.; Fenimore, P. W.; Jansson, H.; McMahon, B. H.; Stroe, I. R.; Swenson, J.; Young, R. D., A unified model of protein dynamics. Proc Natl Acad Sci U S A 2009, 106 (13), 5129-5134.

42. Stadler, A. M.; Demmel, F.; Ollivier, J.; Seydel, T., Picosecond to nanosecond dynamics provide a source of conformational entropy for protein folding. Phys Chem Chem Phys 2016, $18(31), 21527-21538$.

43. Luby-Phelps, K., The physical chemistry of cytoplasm and its influence on cell function: an update. Mol Biol Cell 2013, 24 (17), 2593-2596.

44. Wheeler, S. E.; Shi, H. F.; Lin, F. C.; Dasari, S.; Bednash, J.; Thorne, S.; Watkins, S.; Joshi, R.; Thomas, S. M., Enhancement of head and neck squamous cell carcinoma proliferation, invasion, and metastasis by tumor-associated fibroblasts in preclinical models. Head Neck-J Sci Spec 2014, 36 (3), 385-392.

45. Wehbe, K.; Filik, J.; Frogley, M. D.; Cinque, G., The effect of optical substrates on microFTIR analysis of single mammalian cells. Anal Bioanal Chem 2013, 405 (4), 1311-1324.

46. Chen, M.; Glenn, J. V.; Dasari, S.; McVicar, C.; Ward, M.; Colhoun, L.; Quinn, M.; Bierhaus, A.; Xu, H. P.; Stitt, A. W., RAGE Regulates Immune Cell Infiltration and Angiogenesis in Choroidal Neovascularization. Plos One 2014, 9 (2), e89548.

47. Telling, M. T.; Campbell, S. I.; Engberg, D.; Marero, D. M.; Andersen, K. H., Spectroscopic characteristics of the OSIRIS near-backscattering crystal analyser spectrometer on the ISIS pulsed neutron source. Phys Chem Chem Phys 2005, 7 (6), 1255-1261. 
48. Fagerberg, L.; Stadler, C.; Skogs, M.; Hjelmare, M.; Jonasson, K.; Wiking, M.; Abergh, A.; Uhlen, M.; Lundberg, E., Mapping the subcellular protein distribution in three human cell lines. J Proteome Res 2011, 10 (8), 3766-3777.

49. Long, J.; Zhang, C. J.; Zhu, N.; Du, K.; Yin, Y. F.; Tan, X.; Liao, D. F.; Qin, L., Lipid metabolism and carcinogenesis, cancer development. Am J Cancer Res 2018, 8 (5), 778-791.

50. Roongta, U. V.; Pabalan, J. G.; Wang, X.; Ryseck, R. P.; Fargnoli, J.; Henley, B. J.; Yang, W. P.; Zhu, J.; Madireddi, M. T.; Lawrence, R. M.; Wong, T. W.; Rupnow, B. A., Cancer cell dependence on unsaturated fatty acids implicates stearoyl-CoA desaturase as a target for cancer therapy. Mol Cancer Res 2011, 9 (11), 1551-1561.

51. Li, J.; Condello, S.; Thomes-Pepin, J.; Ma, X.; Xia, Y.; Hurley, T. D.; Matei, D.; Cheng, J. X., Lipid Desaturation Is a Metabolic Marker and Therapeutic Target of Ovarian Cancer Stem Cells. Cell Stem Cell 2017, 20 (3), 303-314.

52. Hilvo, M.; Denkert, C.; Lehtinen, L.; Muller, B.; Brockmoller, S.; Seppanen-Laakso, T.; Budczies, J.; Bucher, E.; Yetukuri, L.; Castillo, S.; Berg, E.; Nygren, H.; Sysi-Aho, M.; Griffin, J. L.; Fiehn, O.; Loibl, S.; Richter-Ehrenstein, C.; Radke, C.; Hyotylainen, T.; Kallioniemi, O.; Iljin, K.; Oresic, M., Novel theranostic opportunities offered by characterization of altered membrane lipid metabolism in breast cancer progression. Cancer Res 2011, 71 (9), 3236-3245.

53. Pascual, G.; Avgustinova, A.; Mejetta, S.; Martin, M.; Castellanos, A.; Attolini, C. S.; Berenguer, A.; Prats, N.; Toll, A.; Hueto, J. A.; Bescos, C.; Di Croce, L.; Benitah, S. A., Targeting metastasis-initiating cells through the fatty acid receptor CD36. Nature 2017, 541 (7635), 41-45. 
54. Tros, M.; Zheng, L.; Hunger, J.; Bonn, M.; Bonn, D.; Smits, G. J.; Woutersen, S., Picosecond orientational dynamics of water in living cells. Nat Commun 2017, 8 (1), 904.

55. Lehuede, C.; Dupuy, F.; Rabinovitch, R.; Jones, R. G.; Siegel, P. M., Metabolic Plasticity as a Determinant of Tumor Growth and Metastasis. Cancer Res 2016, 76 (18), 5201-5208.

56. Luo, X.; Cheng, C.; Tan, Z.; Li, N.; Tang, M.; Yang, L.; Cao, Y., Emerging roles of lipid metabolism in cancer metastasis. Mol Cancer 2017, 16, 76.

57. Ruggiero, M. R.; Baroni, S.; Pezzana, S.; Ferrante, G.; Geninatti Crich, S.; Aime, S., Evidence for the Role of Intracellular Water Lifetime as a Tumour Biomarker Obtained by In Vivo Field-Cycling Relaxometry. Angew Chem Int Ed Engl 2018, 57 (25), 7468-7472.

58. Ziegler, Y. S.; Moresco, J. J.; Tu, P. G.; Yates, J. R., 3rd; Nardulli, A. M., Plasma membrane proteomics of human breast cancer cell lines identifies potential targets for breast cancer diagnosis and treatment. PLoS One 2014, 9 (7), e102341.

59. Roy, J.; Wycislo, K. L.; Pondenis, H.; Fan, T. M.; Das, A., Comparative proteomic investigation of metastatic and non-metastatic osteosarcoma cells of human and canine origin. PLoS One 2017, 12 (9), e0183930.

60. Azrad, M.; Turgeon, C.; Demark-Wahnefried, W., Current evidence linking polyunsaturated Fatty acids with cancer risk and progression. Front Oncol 2013, 3, 224.

61. May-Wilson, S.; Sud, A.; Law, P. J.; Palin, K.; Tuupanen, S.; Gylfe, A.; Hanninen, U. A.; Cajuso, T.; Tanskanen, T.; Kondelin, J.; Kaasinen, E.; Sarin, A. P.; Eriksson, J. G.; Rissanen, H.; Knekt, P.; Pukkala, E.; Jousilahti, P.; Salomaa, V.; Ripatti, S.; Palotie, A.; Renkonen-Sinisalo, L.; Lepisto, A.; Bohm, J.; Mecklin, J. P.; Al-Tassan, N. A.; Palles, C.; Farrington, S. M.; Timofeeva, M. N.; Meyer, B. F.; Wakil, S. M.; Campbell, H.; Smith, C. G.; Idziaszczyk, S.; Maughan, T. S.; Fisher, D.; Kerr, R.; Kerr, D.; Passarelli, M. N.; 
Figueiredo, J. C.; Buchanan, D. D.; Win, A. K.; Hopper, J. L.; Jenkins, M. A.; Lindor, N. M.; Newcomb, P. A.; Gallinger, S.; Conti, D.; Schumacher, F.; Casey, G.; Aaltonen, L. A.; Cheadle, J. P.; Tomlinson, I. P.; Dunlop, M. G.; Houlston, R. S., Pro-inflammatory fatty acid profile and colorectal cancer risk: A Mendelian randomisation analysis. Eur J Cancer 2017, $84,228-238$.

62. Born, B.; Kim, S. J.; Ebbinghaus, S.; Gruebele, M.; Havenith, M., The terahertz dance of water with the proteins: the effect of protein flexibility on the dynamical hydration shell of ubiquitin. Faraday Discuss 2009, 141, 161-173.

63. Ebbinghaus, S.; Kim, S. J.; Heyden, M.; Yu, X.; Heugen, U.; Gruebele, M.; Leitner, D. M.; Havenith, M., An extended dynamical hydration shell around proteins. Proc Natl Acad Sci US A 2007, 104 (52), 20749-20752.

64. Fogarty, A. C.; Laage, D., Water dynamics in protein hydration shells: the molecular origins of the dynamical perturbation. J Phys Chem B 2014, 118 (28), 7715-7729.

65. Bellissent-Funel, M.; Chen, S. H.; Zanotti, J., Single-particle dynamics of water molecules in confined space. Phys Rev E Stat Phys Plasmas Fluids Relat Interdiscip Topics 1995, 51 (5), $4558-4569$

\section{ASSOCIATED CONTENT}

The following files are available free of charge.

Supporting Information (PDF) - Experimental details; supporting Figures associated to the QENS results (S1 and S2).

\section{AUTHOR INFORMATION}




\title{
Corresponding Author
}

*almbc@uc.pt

Unidade de I\&D Química-Física Molecular

Department of Chemistry, University of Coimbra

Rua Larga, 3004-535 Coimbra, PORTUGAL

\section{Author Contributions}

The manuscript was written through contributions of all authors. All authors have given approval to the final version of the manuscript.

\begin{abstract}
ABBREVIATIONS
SR, synchrotron radiation; QENS, quasi-elastic neutron scattering; MAP, methotrexate, adriamycin, and cisplatin; MIRIAM, Multimode Infrared Imaging And Microspectroscopy; EXAFS, X-ray Absorption Fine Structure; PBS, phosphate buffer saline; RMieS, Resoant Mie Scattering Correction; PCA, principal component analysis.
\end{abstract}




\section{Chemotherapeutic Targets in Osteosarcoma}

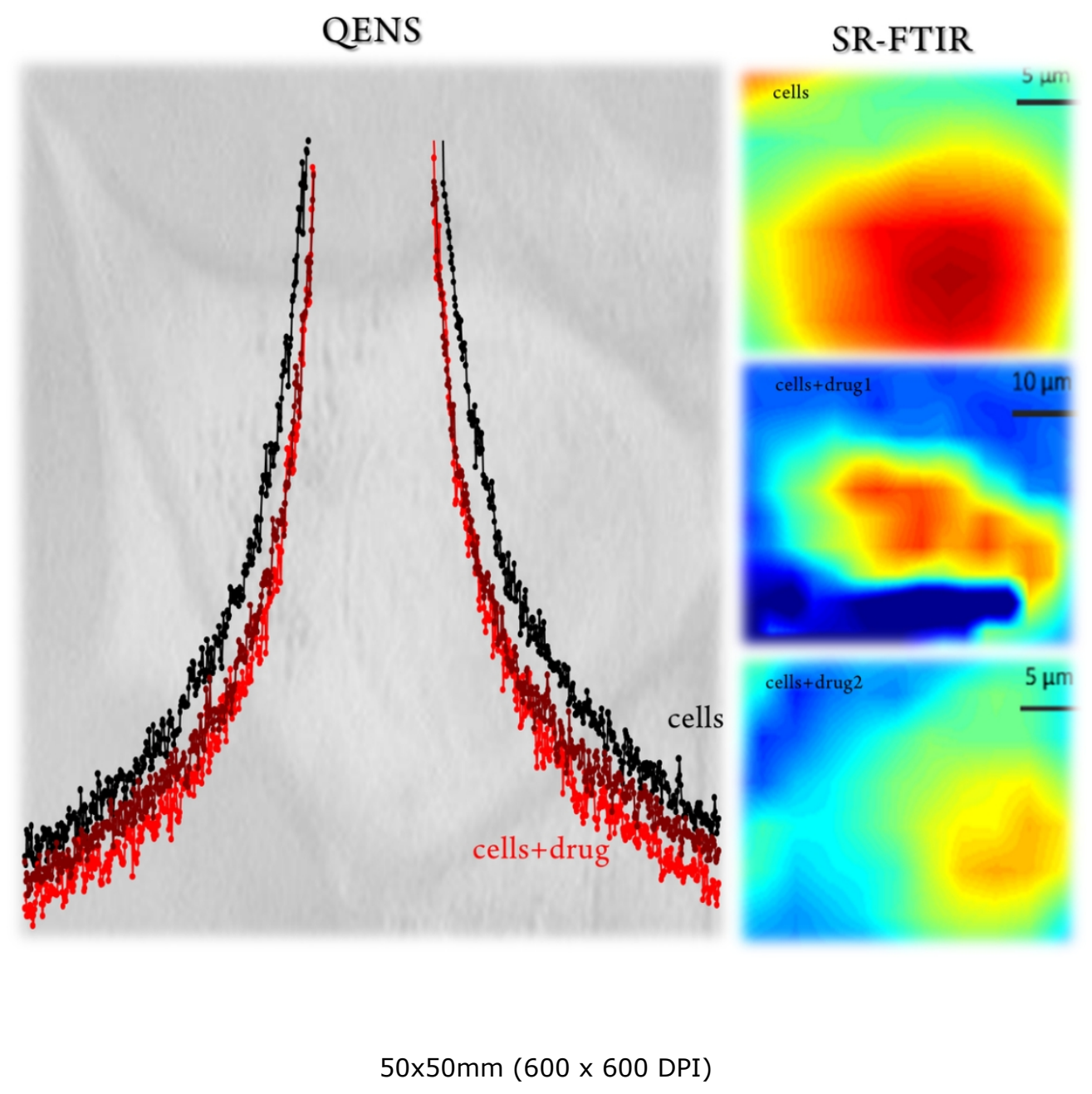

